\title{
NOTES ON THE BIOLOGY OF CIRRIPEDES
}

\author{
By K. A. Pyefinch
}

Biologist, The Corrosion Committee, British Iron and Steel Research Association. From the Marine Station, Millport

(Text-figs. I-I8)

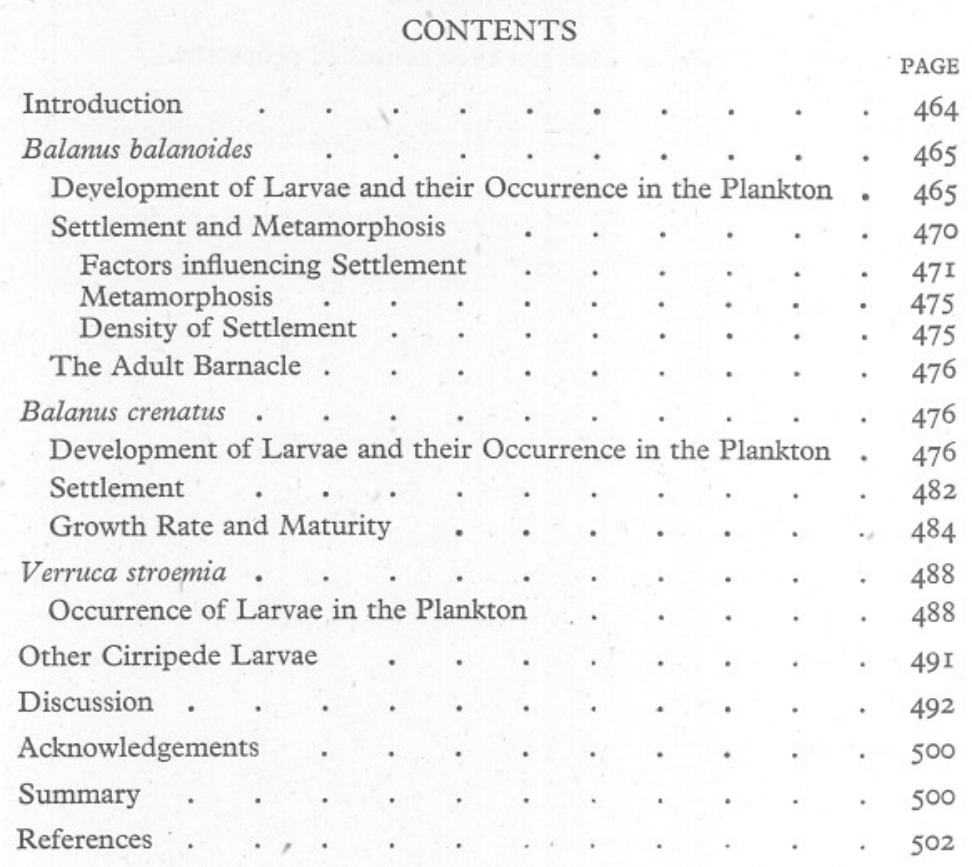

\section{INTRODUCTION}

In the course of some four years' work on the fouling problem opportunities have occurred for observations on the general biology of those barnacles whose larvae occur commonly in the plankton and settle in some numbers on surfaces continuously immersed below experimental rafts at Millport.

In his account of the Crustacea of the Clyde sea area, Scott (I90I) recorded the presence of the following six free-living species of Cirripedes: Balanus porcatus Costa, B. crenatus Brug., B. balanoides (Linn.), B. hameri (Ascan.), Verruca stroemia (O. F. Müll.), and Scalpellum vulgare Leach.

Two parasitic forms, Sacculina carcini (Thomp.) and Peltogaster paguri (Rathke), were also recorded then. In the Annual Reports of the Scottish 
Marine Biological Association for 1919 and 1920 the records of Chthamalus stellatus (Poli), Lepas anatifera $\mathrm{L}$. and $L$. pectinata Spengler were added to this list, and more recently Moore \& Kitching (1939) have estimated the abundance of Chthamalus stellatus on the shores of the Isle of Cumbrae.

Examination of tow-nettings shows that the larvae of Balanus crenatus, $B$. balanoides and Verruca stroemia are by far the most common Cirripede larvae in the plankton. The larvae of Sacculina occur in small numbers, chiefly from November to March; the larvae of Peltogaster paguri have been recorded practically the year round, and on occasions nauplii and cyprids which cannot be referred with certainty to their species have been present; it is possible that these are the larval stages of Balanus porcatus.

On submerged surfaces, the most common species have been $B$. crenatus and B. balanoides. Verruca stroemia, in spite of its abundance in the plankton, has not yet been recorded on a raft-exposed surface. Small numbers of Balanus porcatus have settled from time to time, but the remaining species listed as known in the Clyde have been represented only by a single specimen of Lepas, which settled on a raft-exposed surface during the summer of 1942. It should be added, however, that the surfaces available for settlement have not, in general, extended for more than about $4 \mathrm{ft}$. below the water surface, and this factor has probably limited the range of settling species. Further, the surfaces available have all been exposed vertically, a condition which may also have had its effect on settlement.

Under these circumstances, observations have chiefly been limited to Balanus balanoides, $B$. crenatus and Verruca stroemia; these are the three species principally discussed in this paper.

\section{BALANUS BALANOIDES}

\section{Development of Larvae and their Occurrence in the Plankton}

Balanus balanoides liberates its larvae at only one period of the year, during the early spring. Elmhirst (1923) states that fertilization of the ova occurs from August to November, and Moore (1935a) that fertilization takes place during November at Port Erin. Observations made in the course of the present study show that by the middle of January the ovigerous lamellae within the mantle cavity contain ova in an advanced stage of development. At this time these lamellae are pale yellow in colour and form firm, discrete masses within the mantle cavity. During the later stages of development of the ova, the colour of the ovigerous lamellae gradually darkens, passing from pale yellow, through yellowish brown to brown and dark brown, finally becoming, as the larvae are ready to hatch, virtually black. These colour changes, presumably due both to the absorption of yolk and to the appearance of dark-coloured structures within the developing larva, afford a means of tracing, roughly, the rate at which the later stages of larval development occur. 
Fig. I shows the results of the examination of a series of small samples of $B$. balanoides (each sample roughly Ioo individuals) during January to May I946, in which the proportion of individuals containing ovigerous lamellae in the five colour stages mentioned in the preceding paragraph are expressed as a percentage of the whole sample. (In Stage I of Fig. I the ovigerous lamellae are pale yellow, in Stage 5 they are black in colour.) From this figure it is evident that development was well advanced.when the observations were started, and that further development took place rapidly, a small percentage of individuals containing larvae ready to hatch first appearing towards the middle of February. The latter group reached its maximum in the population examined on 8 March and thereafter showed a general decline in importance,

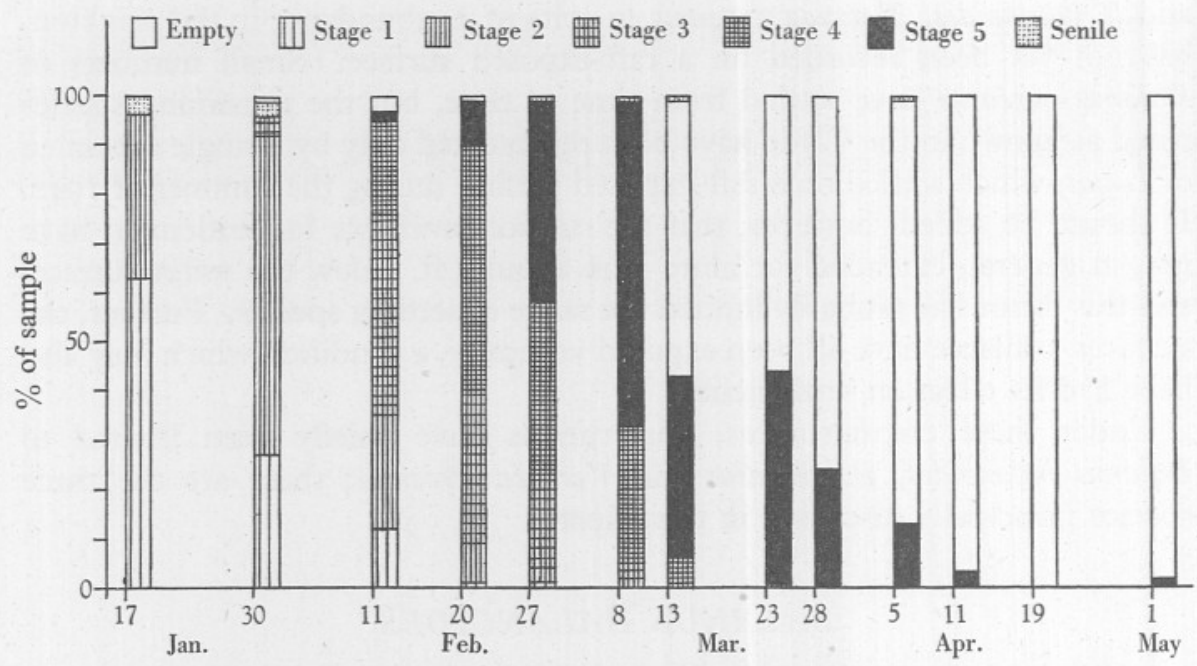

Fig. I. Balanus balanoides. State of development of ova, 1946 .

though $2 \%$ of the individuals examined on I May contained fully developed larvae. Spent individuals were first evident on $\mathrm{I}_{3}$ March and from then onwards progressively dominated the samples examined. These samples of $B$. balanoides were all collected below mid-tide level, that is, from a level below that termed B I by Moore (I935b).

Contemporaneous plankton hauls clearly indicate that the period at which most adults contain larvae ready to hatch corresponds with the appearance of large numbers of Ist and 2nd stage nauplii in the plankton, and suggest that in this species there is a short period when the majority of the adults liberate their larvae. In 1946 the numbers of these larvae present in the plankton were at a maximum on 7 March. Comparable liberations have occurred in the other years covered by these observations: in 1944 the heaviest swarms occurred on I6 March, in I945 the maximum occurred on I4 March (though numbers 
were small in comparison with other years), and in 1947 the greatest numbers were present on II March, though considerable numbers were present from 5 to I4 March.

Following the methods described in a previous paper (Pyefinch, I948), it has been possible to trace the appearance and relative abundance of the later larval stages in the plankton, and the results for 1947 are given in Fig. 2. In this figure the average numbers of each stage present, over 3-day periods, have been expressed as a percentage of the total numbers of $B$. balanoides larvae present over each period. These and all other plankton hauls mentioned in this paper have been made from Keppel Pier, Millport; the conditions which allow such hauls to be made from this pier have been described in the Annual Report of the Scottish Marine Biological Association for 1922 (p. 7). The nets were fished for I hr. daily, starting I hr. after high water. Variations in tidal flow between a neap and a spring tide are, of course, considerable and this factor alone makes this method of tow-netting useless for any but the most approximate quantitative comparisons; it is for this reason that the data given in Fig. 2 are presented as percentages rather than as absolute numbers. The latter are too strongly influenced by variations in the speed of tidal flow. ${ }^{1}$

Ist and 2nd stage nauplii (which may be considered together because the length of life of the Ist stage is very much shorter than that of the 2nd stage) were first present in small numbers on 20 February, 3 rd and 4 th stage nauplii first appeared on $4 \mathrm{March}$, 5th stage nauplii followed on Io March, 6th stage nauplii on I3 March and the first cyprids were recorded on 22 March. This suggests that roughly I month elapses between hatching and the appearance of the cyprid. Moore (I935a), quoting Johnstone, Scott \& Chadwick (I924), states that 2 months separate the naupliar and cyprid maxima in Port Erin Bay, but as the larval stages were not specifically identified, it is possible that this is an over-estimate, covering more than one species.

The histograms shown in Fig. 2 also suggest that at least three maxima of $3^{\text {rd }}$ and $4_{\text {th stage nauplii occurred, and indications of corresponding maxima }}$ are also present for the 5 th and 6 th naupliar stages. From the dates of occurrence of these maxima it is possible to make tentative suggestions of the life periods of the naupliar and cyprid stages; for the first two maxima shown in Fig. 2 these appear to be as in Table I.

As these estimates are based on 3-day averages, the shortest possible interval is 3 days. The differences in interval indicated in this table, therefore, with the exception of the interval between the 6th stage nauplius and the cyprid of the first 'brood', probably mean little and it would seem that the length of life of each larval stage is approximately the same, except that of the Ist naupliar stage which, as noted earlier, may be much shorter.

1 As an indication of the numbers of larvae taken, the following are the average daily hauls, over the period shown in Fig. 2, for each larval stage: Nauplius I+II, 2430; Nauplius III, I525; Nauplius IV, I915; Nauplius V, 870; Nauplius VI, 710; Cyprid, I750. 

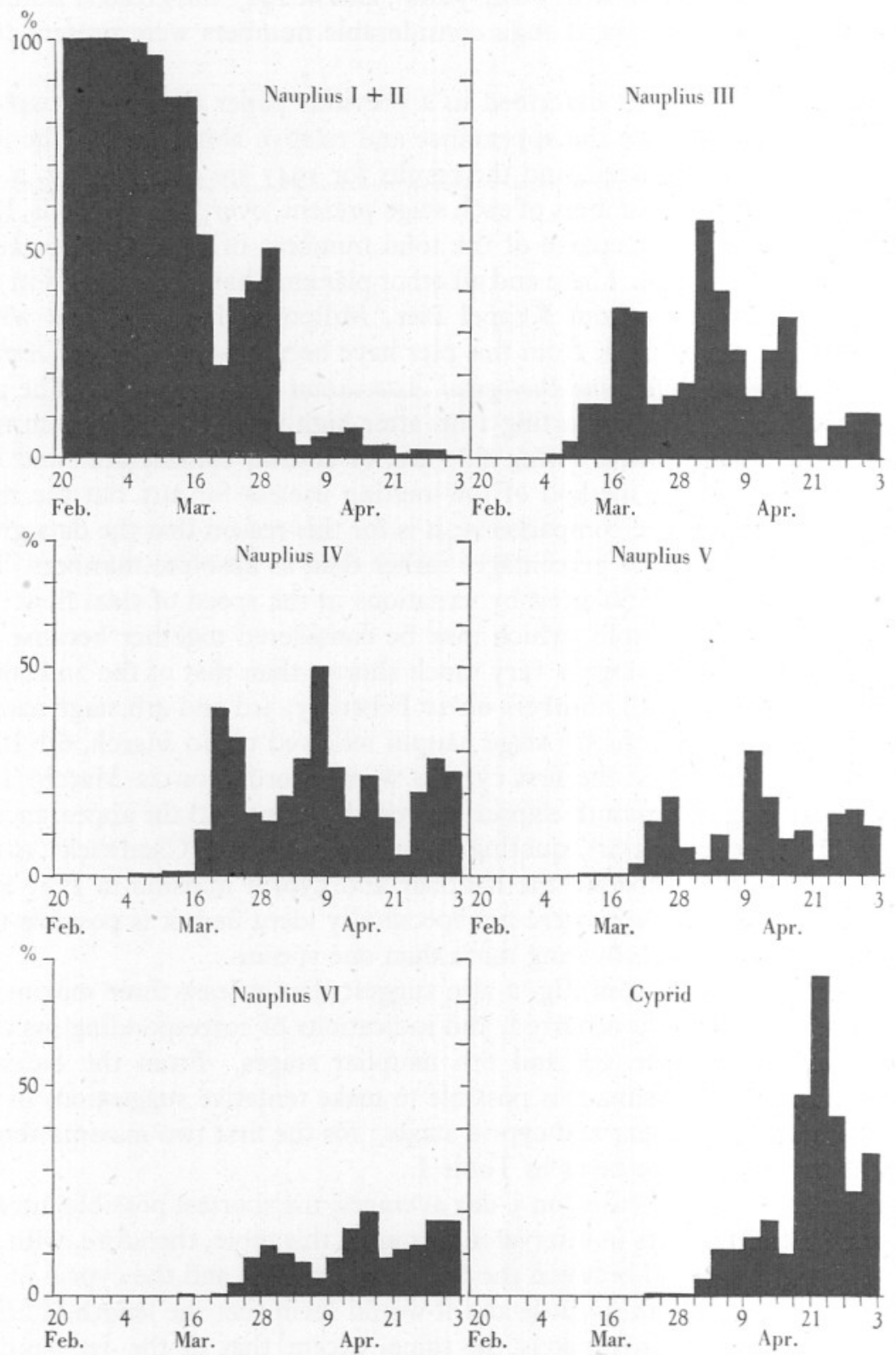

Fig. 2. Occurrence of the larval stages of Balanus balanoides, spring 1947. The numbers present, over 3-day periods, of each larval stage are expressed as a percentage of the total $B$. balanoides larvae present. 


\section{Table I. Rate of Development of BALANUS baLANOIDES}

$\begin{array}{lcccc}\text { Larval stage } & \begin{array}{c}\text { Date beginning } \\ \text { 3-day period } \\ \text { of maximum }\end{array} & \begin{array}{c}\text { Interval } \\ \text { (days) }\end{array} & \begin{array}{c}\text { Date beginning } \\ \text { 3-day period } \\ \text { of maximum }\end{array} & \begin{array}{c}\text { Interval } \\ \text { (days) }\end{array} \\ \text { Nauplius I and II } & \text { Io. iii. } & - & \text { 28. iii. } & - \\ \text { Nauplius III } & \text { I6. iii. } & 6 & 3 \text { I. iii. } & 3 \\ \text { Nauplius IV } & \text { I9. iii. } & 3 & 6 . \text { iv. } & 3 \\ \text { Nauplius V } & \text { 25. iii. } & 6 & 9 . \text { iv. } & 6 \\ \text { Nauplius VI } & \text { 28. iii. } & 3 & \text { I5. iv. } & 6 \\ \text { Cyprid } & \text { ? I2. iv. } & \text { ? I5 } & \text { 2I. iv. } & 6\end{array}$

The interval between the 6th stage nauplius and the cyprid of the first 'brood' seems almost certainly too long and there are reasons for supposing that it has been caused by the action of other factors, which will be more fully discussed later (see p. 498). For the present it may be mentioned that it seems likely that the first 'brood' of nauplii was relatively unsuccessful, in the sense that they eventually produced only a small proportion of cyprid larvae; in this respect the second 'brood' was much more successful. The numbers of ist and 2nd stage nauplii involved in the second maximum-that for the period beginning $28 \mathrm{March}$ (Fig. 2) - were only about $35 \%$ of those involved in the first maximum, yet over $45 \%$ of these were recorded in the cyprid stage, whereas under I $5 \%$ of the first maximum were so represented. The number of cyprid larvae recorded from the later hatched nauplii was actually slightly greater than that produced from the earlier group.

The length of life of the cyprid stage is difficult to assess. Visscher (I928) states that the free-swimming period of the cyprid lasts from 3 days to 2 weeks or longer. Observations made on the cyprid of B. balanoides, taken from the plankton and stored in tanks in the laboratory, suggest that on the average a period of 5 days elapses before settlement begins. Such an estimate, based on artificial laboratory conditions, is not likely to be accurate and field observations suggest that the interval before settlement is much shorter as, when cyprid larvae are present in large numbers in the plankton, settlement on the shore is virtually coincident with the appearance of these swarms.

Visscher (loc. cit.) further states that the oil globules, which are present in some numbers in the tissues of the cyprid, particularly towards the anterior end, disappear towards the end of the free-swimming period. It has not been possible to confirm this observation, either for the cyprid of B. balanoides or for that of $B$. crenatus. McDougall (I943) states that he has confirmed Visscher's observation for B. eburneus but has not found that the oil globules of the cyprid of Chthamalus fragilis disappear. Nevertheless, it seems possible that physiological changes do take place during the free-swimming life of the cyprid, changes which must have reached a certain stage before settlement can occur; it is hoped to discuss this point more fully in a later paper.

These notes on the larval stages of $B$. balanoides have chiefly been based on observations made during I947; the main outline of the story-liberation of 
larvae during the first half of March, appearance of nauplii of the 3 rd and later stages during the second half of that month and first appearance of cyprid larvae late in March or early in April-has been fully confirmed by the observations of the preceding 3 years. The differences between one year and another present some features of general interest, which are discussed more fully later in this paper.

\section{SETTLEMENT AND METAMorphosis}

Settlement of the cyprid of B. balanoides occurs during April and, over the 4 years covered by this survey, seems to occur most heavily towards the beginning of that month.

Two methods of locomotion are commonly used by the cyprid larva: a swimming motion produced by rapid movements of the thoracic appendages, and a walking motion in which the tips of the antennae are used. It is also of interest to find that the normal response to a slight increase in speed of water movement is one of attachment to the surface; a weak current of water from a pipette can stimulate this clinging reaction and if the water is poured out of a dish or beaker containing $B$. balanoides, the majority of the larvae will remain clinging to the walls of the container. This response is not shown by the cyprid of B. crenatus; it is one which would seem of particular importance for an intertidal form. It is not known how far such temporary 'attachments' become permanent; in the laboratory they do not, but there the surfaces to which the cyprid clings are often widely different from those which it would encounter under natural conditions.

Some observations have been made on the cement by means of which secure attachment to the substratum is attained. It is clear that this takes place in two stages. Primarily, permanent attachment is secured by means of a large mass of cement, produced from the cement glands of the cyprid, which surrounds the bases of the antennae. After metamorphosis, this mass of cement lies approximately at the centre of the basis of the young barnacle and for some time constitutes the sole means of attachment to the substratum, so that the barnacle can be rotated about this central, pillar-like support. Later a thin layer of cement is secreted all over the basis, which then becomes attached to the substratum over the whole of its area.

The staining reactions of the cement, both of that secreted by the cyprid and of that secreted later by the young barnacle suggest, as Yonge (1938) has pointed out, that this secretion is identical with the cuticular layer of the integument. This would suggest that the setting of the cement might take place as a result of a similar series of reactions to those outlined by Pryor (1940). Some preliminary observations were made along these lines in the course of this work, but these need considerable amplification before it can be stated that the setting of the attachment cement is due to the 'tanning' of a muco-protein. 


\section{FACTORS INFLUENCING SETTLEMENT}

Many workers have investigated the factors which seem to affect barnacle settlement, but it is difficult to find much unanimity of opinion as to the relative importance of the various factors concerned. The range of species covered in these investigations is, however, considerable and, as it is reasonable to suppose that any one factor will not necessarily play as important a part in influencing settlement of one species as it will with another, confusion may have arisen because of the range of species used as experimental material. The following notes apply only to the settlement of $B$. balanoides on structures continuously immersed; contrary to general experience, these studies have shown that this species can settle, metamorphose and grow on such surfaces, though settlement is probably less dense than on intertidal surfaces.

Nature of the Surface. In the course of its 'walking' motion over a surface, a cyprid can cover appreciable distances (Visscher, I928, records that this type of motion may persist for an hour, during which a distance of the order of I2 $\mathrm{mm}$. can be covered) and it is therefore possible for the larva to encounter a range of surface conditions, some of which may be more suitable for settlement than others. Primarily, settlement is usually confined to cracks, crevices and other irregularities of the surface, though, if the supply of settling stages is maintained, this distinction may later disappear. Pomerat \& Weiss (I946) have recently described the extent to which settlement can occur on a wide range of substrata and have found wide variations in the populations of barnacles (B. improvisus and B. amphitrite niveus) which settled on these surfaces during an exposure period lasting 3 months. The results of exposures of a number of different types of surface during the settlement period for B. balanoides in 1944, when cyprid larvae were particularly abundant, are given in Table II.

\section{Table II. Density of Settlement of B. BALANoides ON DIFFERENT SURFACES}

$\quad$ Coating applied
Anti-corrosive paint
(non-toxic)
Cementiferous protective
composition
Rosin-paraffin wax
Stearic acid
Petroleum jelly-paraffin
wax mixture
Zinc ricinoleate

Aluminium ricinoleate

$\begin{array}{lc}\text { Nature of surface produced } & \begin{array}{c}\text { Density of settlement } \\ \text { No./sq.in. }\end{array} \\ \begin{array}{l}\text { Smooth; slight surface } \\ \text { irregularities }\end{array} \\ \begin{array}{l}\text { Granular } \\ \text { I05 }\end{array} \\ \text { Waxy } & 77 \\ \text { Fatty } & 90 \\ \text { Greasy } & 68 \\ \text { Surface completely covered with } & \text { I } \\ \text { a heavy, jelly-like slime over } & \\ \text { period of settlement } & \text { I } \\ \text { Surface completely covered with } \\ \text { a very heavy, jelly-like slime } \\ \text { over period of settlement }\end{array}$

Density of settlement o./sq.in.

JOURN. MAR. BIOL. ASSOC. vol. XXVII, 1948 
Though settlement on the non-toxic paint surface proved heavier than that on the other types of surface exposed, settlement occurred to an appreciable extent on all surfaces except those covered with slime and that which had a greasy, unstable finish. The slime which developed on the metallic soap surfaces exposed was far heavier and more viscous than that which often develops on a painted surface, but observations made by Dr M. F. Spooner (personal communication) suggest that the latter type of slime (which is most commonly bacterial in origin) can be as effective in preventing settlement. During a very heavy settlement of the cyprid of $B$. balanoides at Caernarvon in April 1943, she noticed that some of the surfaces exposed had acquired a slime film, which in places was stripping away; settlement of cyprids was wholly confined to those areas thus denuded of slime.

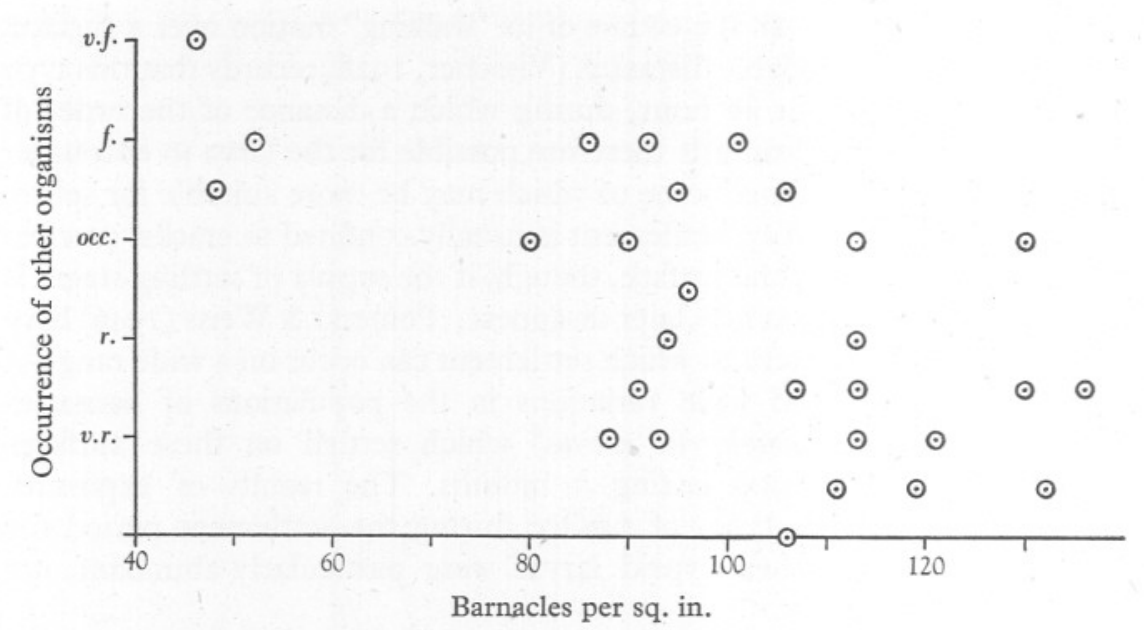

Fig. 3. Effect of the presence of other organisms on the density of settlement of Balanus, balanoides. The former is classed in eight grades, ranging from 'none' to 'very frequent', (v.f.); alternate intermediate grades are denoted 'very rare' (v.r.), 'rare' (r.), 'occasional' (occ.), and 'frequent' $(f$.$) .$

Presence of Other Organisms. Fig. 3 shows the relationship between the density of settlement of $B$. balanoides and the presence of other sedentary forms; in general, the presence of other organisms in any numbers would seem markedly to reduce the density of settlement of this species of barnacle. It should perhaps be added that the other organisms present on these surfaces were Obelia, Ectocarpus and Enteromorpha, since the type of organism present is clearly important; a surface covered with Mytilus or with other barnacles will not interfere with settlement to the same extent.

Light and Water Currents. A number of workers (Visscher, I928; Visscher \& Luce, I928; Neu, I933), have investigated the effect of light on the settlement of the cyprid larva of a number of barnacle species, and generally seem to 
have concluded that this larva reacts negatively to light at the time of its attachment and that barnacle settlement takes place most readily on shaded surfaces. The colour of the substratum has also been found to be of importance, settlement of the cyprid taking place most readily on darker colours (Visscher \& Luce, I928). In their study of the effect of surface angle and of light on the attachment of barnacles, Pomerat \& Reiner (I942) conclude that the photic factor is of primary importance in the attachment of Balanus eburneus. McDougall (I943), however, suggests that the effect of the quantity and quality of the incident light and the tone of the surface of submerged objects, though they influence the settlement of the cyprid, need further investigation before their action can be regarded as definite.

In the course of this work a series of exposures was made which illustrates the difficulty of drawing definite conclusions on the effect of light on settlement. In the spring of 1944 a number of mild steel panels, each 24 in. $\times 24$ in., coated with a non-toxic paint, were exposed to investigate variations in density of settlement over a limited area. The upper edges of the panels lay some I8 in. below the surface and the fifteen panels exposed were distributed at random through the seven exposure bays available on the raft used for this experiment (see Fig. 4). Settlement of the cyprids of B. balanoides was heavy during April I944, and at the end of this period the panels were withdrawn and the density of settlement estimated, for each panel, by counting the numbers of barnacles present with 2 in. $\times 2$ in. areas chosen at random from each square foot of each face of each plate. Eight areas were thus counted for each panel. The mean density (as individuals/sq.in.) for each face of each plate is given in Fig. 4.

The exposure conditions of the panels situated at the end positions in each bay differed from those situated towards the centre of the bays in that the face towards the outside of the raft (i.e. those towards the nearest end of each bay) was shaded by the presence of a buoyancy drum lying immediately outside it. Inspection of the density of settlement on these faces shows that it was always higher than on the inner, better lit face. This suggests heavier settlement on the shaded surfaces; but an inspection of the density of settlement on the more centrally-situated panels shows similar-or even greater-differences between the two faces of most of them. The lighting of the two faces of these panels was certainly more equal than it was for panels exposed at the ends of the bays and therefore, if light were the most important factor concerned, a greater similarity in density of settlement should have occurred.

Walton Smith (I946) has recently drawn attention to the effect of water currents on the settlement of.barnacles and his experiments have shown that permanent settlement of the cyprid can be prevented by currents of the order of I knot or less. This factor may clearly also play a part in controlling density of settlement. In the experiments under discussion, those panels at the ends of the bays are not only shaded on their outer faces, but these faces may possibly also, because of the buoyancy drums outside them, be in 'dead' water for 
slightly longer periods in each tidal cycle. The limiting current speed for B. balanoides is not known, but it would seem possible to suppose that this was exceeded for slightly shorter periods per tidal cycle for the outer faces of these panels than for their inner faces and, given the presence of a considerable number of settling larvae, this might therefore lead to heavier settlement on the outer faces.

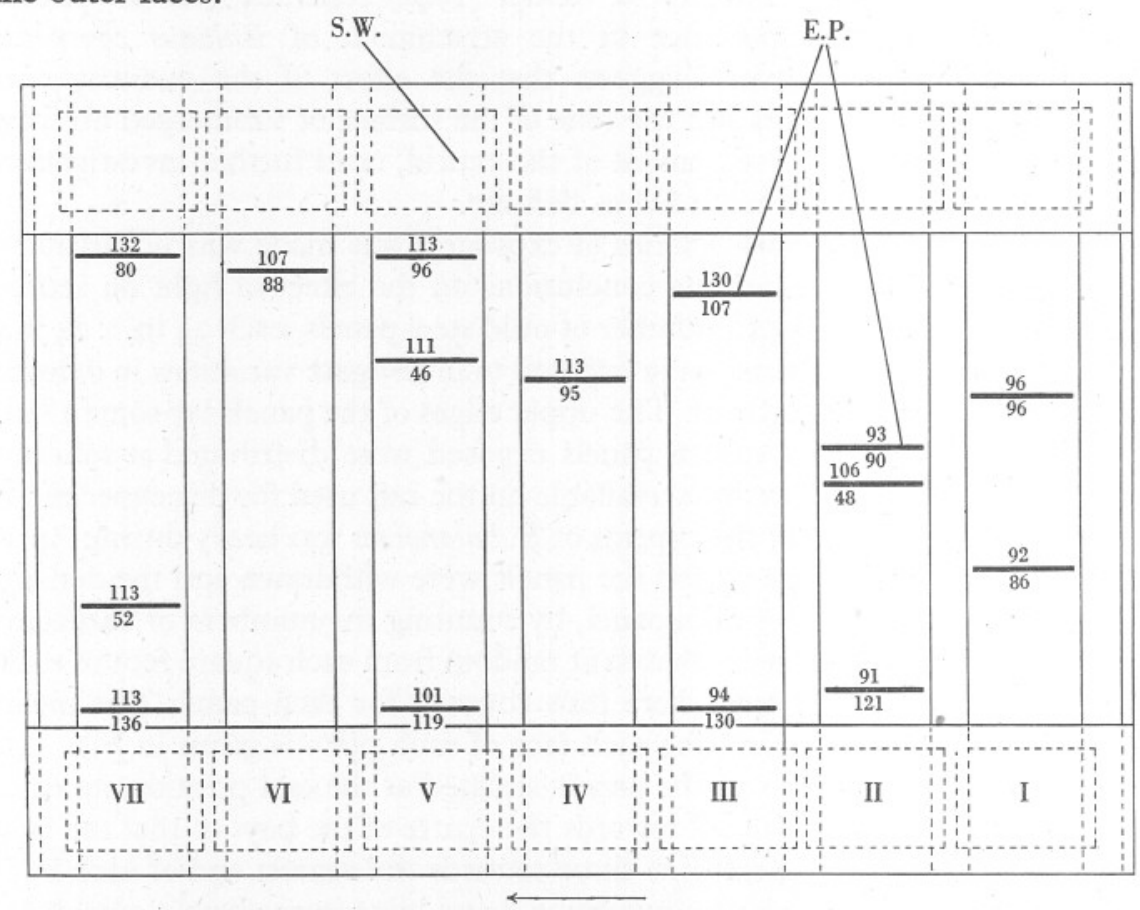

Fig. 4. Plan of raft, showing positions of exposures for observations on the density of settlement of Balanus balanoides. The roman numerals indicate the numbers of the exposure bays. The arabic figures, set against each side of the exposure panels (E.P.), represent density of barnacles, as explained in the text. S.w., side-walk with the buoyancy drums beneath. The arrow at the foot of the plan represents direction of the ebb tidal flow. The raft is moored with its ends facing NNE. (bay I) and SSW. (bay vII).

The possibility that current speeds play some part in influencing density of settlement also means that the occurrence of differences in density of settlement on the two faces of panels immersed towards the middle of these bays is less anomalous than if light were the sole controlling factor. This raft is moored so that its long axis lies approximately parallel with the tidal current but the panels suspended from it are not orientated accurately edge on to this current, hence it is possible that this, coupled with the effects of neighbouring panels, might lead to differences in the period of slack water per tidal cycle on the two faces of the panels, and so to differences in density of settlement. Other exposures suggest that marked differences in water flow may be present. 
At the site where this exposure raft is moored, the ebb tide (indicated by an arrow on Fig. 4) is far stronger than the flow. If this suggestion of the effect of water currents is correct, therefore, those panels situated towards the middle of the end bay on the 'ebb end' of the raft should, because of the absence of interference from either buoyancy drums or other panels, be likely to show the most similar conditions on their two faces. It is therefore interesting to find that the population densities on the two faces of the panels immersed in this position (i.e. towards the centre of bay I, see Fig. 4), are virtually identical.

It is clear that this hypothesis that current speeds play at least as important a part in affecting settlement as light can only be advanced tentatively, but laboratory evidence does not indicate that the cyprid of $B$. balanoides reacts negatively to light at the time of attachment. If these larvae are kept in a tank lit from one side, they cluster thickly on the lighted face. Settlement usually begins elsewhere in the tank, but later, when death and settlement have reduced the numbers of free-swimming larvae swarming over the lighted face, settlement takes place readily there, which suggests that lack of settlement over this face initially was due to the mechanical interference of large numbers of free-swimming forms. If the numbers of cyprids are reduced so that crowding on the lighted face is not excessive, settlement starts on that face.

Mention has been made earlier in this section of the effect of colour of substratum on settlement. This survey has provided little additional evidence, which can be regarded as at all conclusive, on this point. Though exposures of non-toxic paint surfaces of different colours, made in I944, did not indicate any marked differences in density of settlement on the various colours employed, conditions of exposure were not critical enough to allow much importance to be attached to this result.

\section{METAMORPHOSIS}

Observations on shore settlements indicate that metamorphosis takes up to $48 \mathrm{hr}$. to be completed; these observations also emphasize the heavy mortality which occurs during this process, as roughly $50 \%$ of the original population observed died during metamorphosis.

\section{DENSITY OF SETTLEMENT}

In the course of other experiments, a number of observations have been made on the density of settlement at various stages. The most relevant observations are given in Table III.

\section{Table III. Population Densities of B. BALANoides at Different Stages}

Stage
Newly settled cyprids
Young barnacles
Young barnacles
Barnacles, over 2 months old

Number/sq.in.
480
I06
76
65

Date and place of record

Millport, April r945 Millport, April I944 Millport, April I945 Carnarvon, July I943 
These observations emphasize the heavy mortality which occurs after settlement, but it should be added that the difference between the newly settled cyprid and the young barnacle populations has possibly been overemphasized, as the former count was made from an intertidal area and may thus include some larvae present on the surface due to the 'clinging' reaction mentioned earlier and which may not have been permanently attached. The density of the 2-month-old population is high compared with that of many intertidal areas, but all the individuals were extremely elongated and resembled the specimens of $B$. balanoides var. elongatus Gould. mentioned by Moore $(1935 b)$.

\section{The Adult BarNacle}

It is interesting to find that B. balanoides, so typically an intertidal form, can settle and metamorphose in some numbers under conditions of continuous immersion. Settlement under these conditions, moreover, is not confined to the region immediately below the water, as an exposure made in 1944 showed that settlement of $B$. balanoides could take place down to a depth of over $5 \mathrm{ft}$. below the water-line. Other records are available (Mr R. Elmhirst, personal communication) of the settlement of $B$. balanoides below low-water mark, e.g. it has been found, though not in large numbers, on Laminaria. No detailed observations have been made on the growth rate of individuals continuously immersed but it was evident to the eye that growth, at any rate over the period immediately following settlement, was more rapid in continuously immersed individuals than in forms which had settled on the shore. As opportunities for feeding are not limited for the individual below the water-line in the way they are for an intertidal specimen, this might be expected. It would be of interest to know more about the general biology of such individuals, since continuous immersion modifies a number of the factors of the normal habitat of this species. For example, such individuals are not subject to the high temperatures which can occur on the shore during the summer and therefore the curious intermittent growth, described by Hatton \& Fischer-Piette (1932), might not occur.

\section{BALANUS CRENATUS}

\section{Development of Larvae and theIr Occurrence in the Plankton}

The breeding habits of $B$. crenatus differ markedly from those of $B$. balanoides for, whereas the latter liberates larvae only over a limited period of the year, $B$. crenatus liberates larvae at intervals from early spring onwards through the summer.

Fig. 5 shows the results of a series of examinations of small populations of this species, similar to those made for $B$. balanoides, over a period extending from mid-January to the beginning of May. Four arbitrary stages could be recognized in the development of the larvae, based upon the colour of the 
ovigerous lamellae. In the Ist stage the ovigerous lamellae were white in colour and creamy in consistency; microscopic examination showed them to contain unsegmented ova. In the 2 nd stage the white colour persisted, but each lamella now formed a discrete mass within the mantle cavity; the ova were beginning to segment. In the 3 rd and 4 th stages, the ovigerous lamellae became coloured; but at first they became much more transparent in appearance and pink or light brown in colour (stage 3), the colour later darkening to a deep purple (stage 4). In stage 3 , the outlines of the larva are clearly visible within each vitelline membrane and the rudiments of the appendages could be detected; in ova from 4 th stage ovigerous lamellae the larva was fully formed and the median eye spot visible.

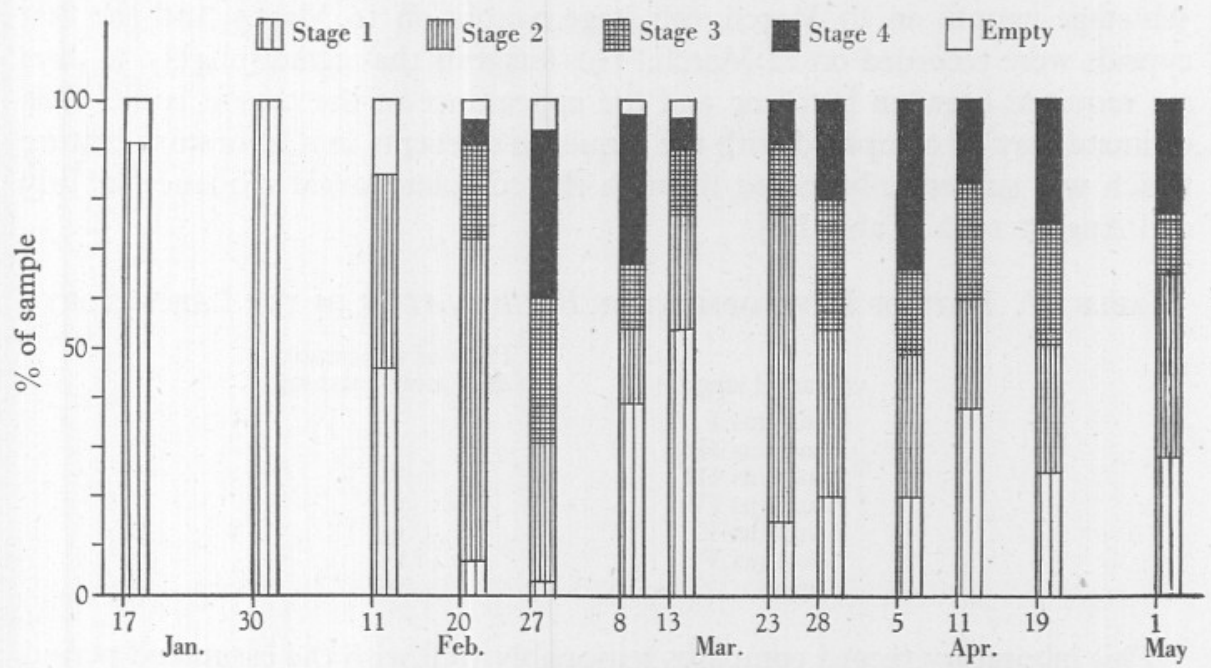

Fig. 5. Balanus crenatus. State of development of ova, 1946 .

A comparison of Fig. 5 and Fig. I suggests that development of the ova started later in B. crenatus than in B. balanoides but, once started, progressed more rapidly as populations of both species showed a small proportion of individuals containing larvae ready to hatch at about the same time. From then onwards some proportion of the barnacles examined contained larvae ready to hatch. Examinations of samples of $B$. crenatus were continued for the rest of the year and individuals containing larvae ready to hatch were last recorded in a sample collected on 30 August. The maximum percentage of individuals containing larvae ready to hatch, however, fell steadily through the summer, in February $34 \%$ was the maximum recorded, in March $30 \%$, in April $34 \%$, May 20\%, June I $\%$, July $8 \%$ and in August $6 \%$. This suggests that over each period of liberation, the numbers of larvae liberated decreased and therefore the numbers of cyprids available for settlement should grow steadily less: fig. 8 confirms this. 
Fig. 6 presents the analysis of counts of B. crenatus larvae for 1947 over the period of the year when they are most abundant-March and April. ${ }^{1}$ Ist and 2nd stage nauplii (which have again been grouped together because the Ist stage moults to give the 2nd stage within a few hours of liberation) first appeared in any numbers during the 3 -day period beginning 20 February. In I946 they first appeared in number on 27 February, in 1945 on 4 March and in I944 on 24 February, so that their appearance in the plankton in 1947 was earlier than in the preceding 3 years. The factors which govern the date on which the early larvae become common in plankton hauls are not known, but there is no direct relationship with water temperature.

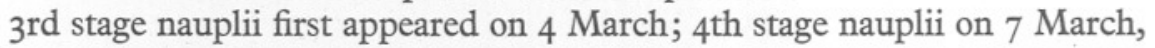
5 th stage nauplii on 13 March, 6th stage nauplii on I6 March, and the first cyprids were recorded on 22 March. This suggests that again roughly 30 days are required between hatching and the appearance of the cyprid larva. This estimate may be compared with the sequence of events in a laboratory culture which was successfully reared through the complete larval sequence in July and August 1942 (Table IV).

Table IV. Rate of Development of B. cRenatus in the Laboratory

Larval stage
Nauplius I
Nauplius II
Nauplius III
Nauplius IV
Nauplius V
Nauplius VI
Cyprid

Time of appearance (days after hatching)

-1
8
11
13
? 15
16

This laboratory record compares reasonably well with the estimated period taken from hatching to the appearance of the cyprid in the sea, when it is remembered that development in the laboratory was carried through at a temperature of $15^{\circ} \mathrm{C}$. or more, and the sea temperatures prevailing during February and March 1947 were $4-5^{\circ} \mathrm{C}$.

Herz (1933), in his account of the larval stages of B. crenatus, described eight naupliar stages. In the course of the present work it has not been possible to discover more than six naupliar stages, of which a detailed description will be given in a later paper. Bassindale (1936) has discussed the validity of the 2nd stage nauplius described by Herz. It would seem unlikely that two species of Balanus should differ in the number of their naupliar stages, when there are no differences of this nature between species belonging to different genera, as B. balanoides, Verruca stroemia and Chthamalus stellatus each have six naupliar stages (Bassindale, I936). It is possible, however, that the number

1 As an indication of the numbers of larvae taken, the following are the average daily hauls, over the period shown in Fig. 6, for each larval stage: Nauplius I+II, 695; Nauplius III, 545; Nauplius IV, I I95; Nauplius V, I560; Nauplius VI, 955; Cyprid, 970. 

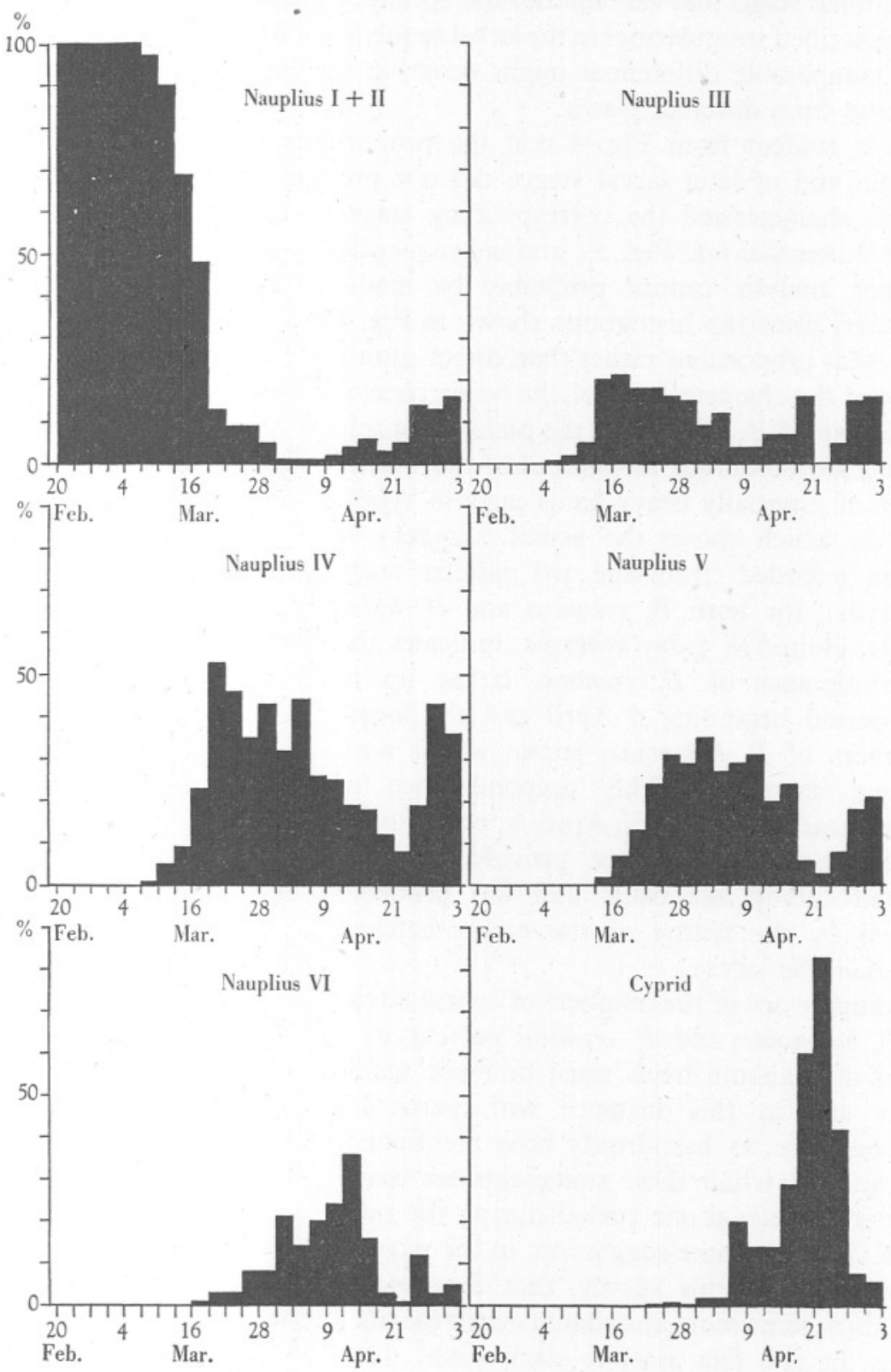

Fig. 6. Occurrence of the larval stages of Balanus crenatus, spring 1947. The numbers present, over 3-day periods, of each larval stage are expressed as a percentage of the total $B$. crenatus larvae present. 
of naupliar stages may vary for the same species. Macdonald (1927), for example, has described irregularities in the larval sequence of Meganyctiphanes norvegica, and comparable differences might occur in the larval sequence of Balanus crenatus from different places.

It is evident from Fig. 6 that the proportions of 3 rd stage $B$. crenatus nauplii and of later larval stages did not provide the sequence of maxima which characterized the corresponding stages of B. balanoides (cf. Fig. 2), and consequently further analysis cannot profitably be made. Further, since the histograms shown in Fig. 6 represent proportions rather than direct counts some of the characteristics of the occurrence of the larvae of B. crenatus in the plankton at this period are obscured, in particular, the occurrence of especially heavy hauls early in April. Fig. 7, which shows the actual numbers of larvae recorded (from the 3 rd naupliar stage onwards), for both $B$. crenatus and B. balanoides, plotted as 3-day averages, indicates the preponderance of $B$. crenatus larvae up to the period beginning 6 April and the larger numbers of $B$. balanoides larvae which were present thereafter. This preponderance of $B$. crenatus larvae early in April is, on the basis of the restricted evidence provided by this limited survey, not usual and was probably caused by the failure of the earlier-hatched $B$. balanoides larvae.

Comparisons of the numbers of cyprid larvae of $B$. balanoides and $B$. crenatus present in a series of plankton hauls must be made tentatively and in this instance with particular caution since, as has already been mentioned, the hauls on which these statements are based were made only at one period during the tidal cycle. There is some suggestion, in the records accumulated in this survey, that $B$. crenatus cyprids become more abundant later in the tide, i.e. as the ebb falls away to slack water. It is

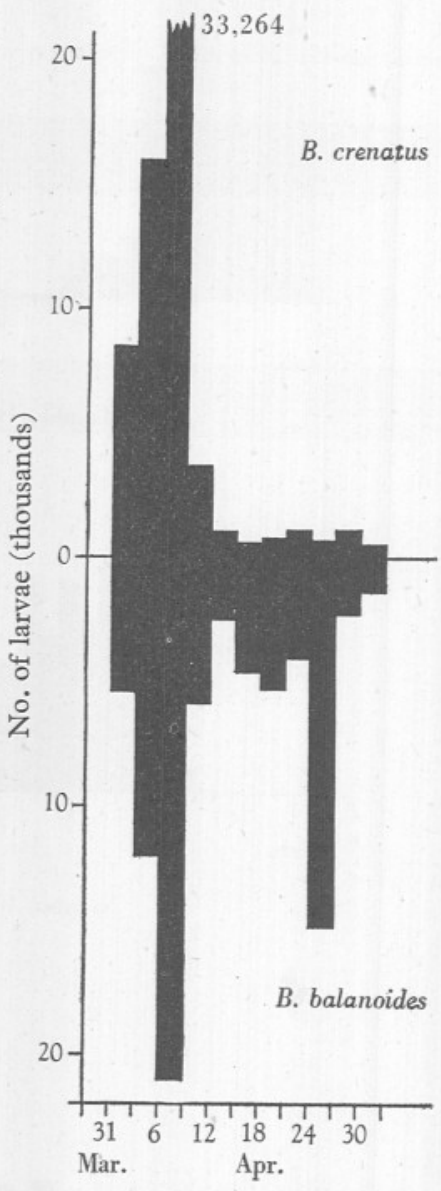

Fig. 7. Numbers of Balanus crenatus and $B$. balanoides larvae present in the plankton during April I947 (shown as 3-day averages).

hoped to investigate this point more fully later but if the point is then substantiated, it is evident that the results just discussed may be erroneous in the emphasis laid on the abundance of the cyprids of $B$. balanoides. This point raises the whole question of the possibility of a relationship between larval 
abundance and the time in the tidal cycle at which hauls were made. Some observations have been made which indicate that such variations do occur, but a fuller investigation, on a more strictly quantitative basis, is needed before the problem can be discussed further.

Earlier in this paper, an attempt was made to estimate the success of larval development of $B$. balanoides by comparing the numbers of cyprids and the numbers of Ist and 2nd stage nauplii. On this basis the February-March liberation of $B$. crenatus nauplii can be counted as successful, as the cyprids recorded early in April represent nearly $70 \%$ of the nauplii hatched at the end of February and early in March.

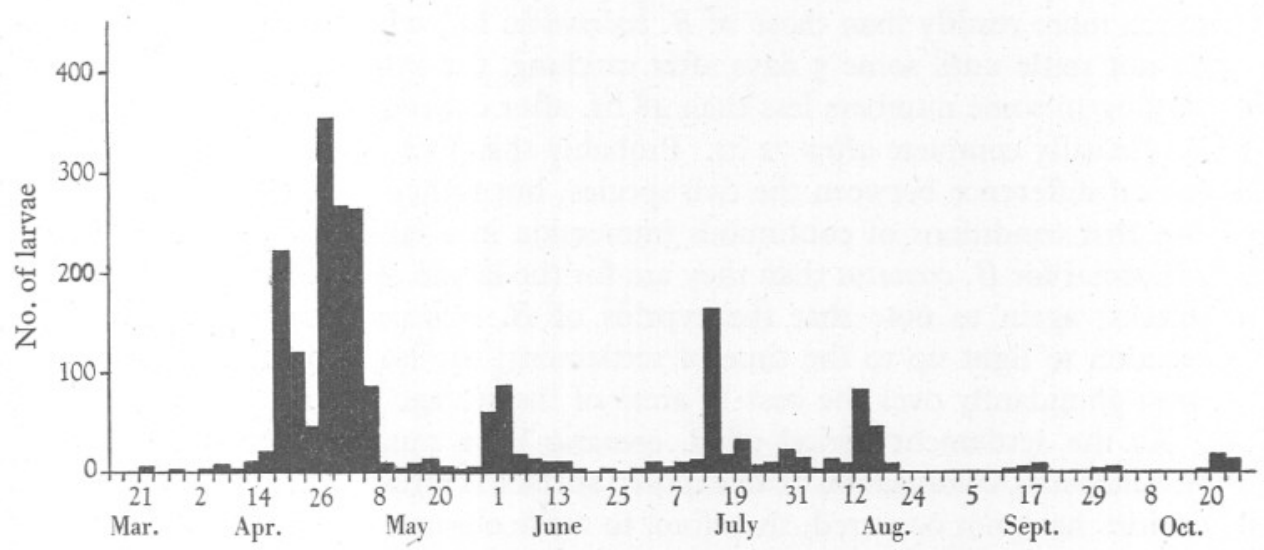

Fig. 8. Occurrence of cyprid larvae of Balanus crenatus, I946. Numbers of larvae per haul in 3-day averages.

Examination of hauls later in the year shows that the larvae of B. crenatus, particularly the later-stage nauplii and the cyprids, are most common at intervals through the summer. Fig. 8 shows the recorded occurrence of the cyprids of $B$. crenatus from mid-March to the end of October 1946. Maxima occurred during April (and especially at the end of that month), at the end of May and in the middle of July and August. As these records are based on hauls made from Keppel Pier, these variations might have been caused by variation in tidal strength between springs and neaps ${ }^{1}$, but as records for the settlement of this species show that this also was periodic, it would seem likely that these plankton records present a true picture of the situation. This periodicity in the reproduction and settlement of $B$. crenatus does not seem to have been recorded before, but it gives rise to marked differences in size between individuals which have settled, some early and some later in the season. On

1 Spring tidal periods were: 3-6, I9-20 Feb.; 5-8, I9-22 Mar.; 5, I8 Apr.; 3, I5-I8, 3I May; I3, 28 June; I2, 27 July; II, 25 Aug.; I3-I5, 24 Sept.; I3-I5, 27 Oct., I946 and 9, 22-26 Feb.; IO-I2, 25 Mar.; 8, 23 Apr., I947. 
occasion, the assumption that $B$. crenatus, like $B$. balanoides, settles only at one period of the year has led to misinterpretations. For example, Foxon (1940) bases statements on the period for which the externa of Sacculina carcini had been in place on the occurrence of specimens of Balanus crenatus of two sizes on the carapace of the host. The crabs were collected in August, so it would seem quite possible that all the $B$. crenatus present had settled during the spring and summer of the same year, and did not, as Foxon supposes, belong to settlements of two successive years.

\section{SETTLEMENT}

On the basis of laboratory observations, the cyprids of $B$. crenatus settle much more readily than those of $B$. balanoides for, whereas the latter usually do not settle until some 5 days after catching, the cyprids of $B$. crenatus are settling in some numbers less than $48 \mathrm{hr}$. after collection and settlement may be virtually complete after $72 \mathrm{hr}$. Probably this does not represent a physiological difference between the two species, but rather is an expression of the fact that conditions of continuous immersion in a tank of sea water are less abnormal for $B$. crenatus than they are for the larvae of B. balanoides. It is of interest again to note that the cyprids of $B$. crenatus retain their positive reaction to light up to the time of settlement; the latter process takes place most abundantly over the best-lit areas of the storage tank.

As the settlement period of $B$. crenatus is so much longer than that of $B$. balanoides, colonization of an exposed surface is rarely so intense and opportunities have not occurred, therefore, to make observations on the conditions affecting settlement of $B$. crenatus comparable with those made for $B$. balanoides, though no indications have been noticed which would suggest that the reactions of the cyprid of $B$. crenatus to slimy or fouled surfaces differ markedly from those of the cyprid of $B$. balanoides.

As might be expected for a species with a normal vertical range lying mainly below low-water mark, $B$. crenatus settles in greater abundance at some distance below the water-line. Table $\mathrm{V}$ gives the density of settlement at various depths on a surface exposed from late June to late August 1945 which is typical of the vertical distribution of this species. In confirmation of the periodicity of settlement, this population was also distinctly bi-modal,

\section{Table V. Vertical Distribution of $B$. cRenatus}

Depth below water-line

$0.5-1 \cdot 5$

$\mathrm{I} \cdot 5-2 \cdot 5$

$2 \cdot 5-3 \cdot 5$

$3.5-4 \cdot 5$

$4 \cdot 5-5 \cdot 5$

$5 \cdot 5-6 \cdot 5$

$6 \cdot 5-7 \cdot 5$

$7 \cdot 5-8 \cdot 5$
Nos.

(barnacles per sq.ft.)

I

IO

8.5

32

$62 \cdot 5$

I $20 \cdot 5$

I 28

100.5 
consisting of a recent settlement-probably early August-and an earlier settlement, probably early July.

From this table it is evident that settlement has been heavier some distance below the water-line; $75 \%$ of the settlement was limited to depths greater than $5 \mathrm{ft}$. It should, however, be emphasized that these data have been obtained from a floating object, since the surface was immersed from a raft.

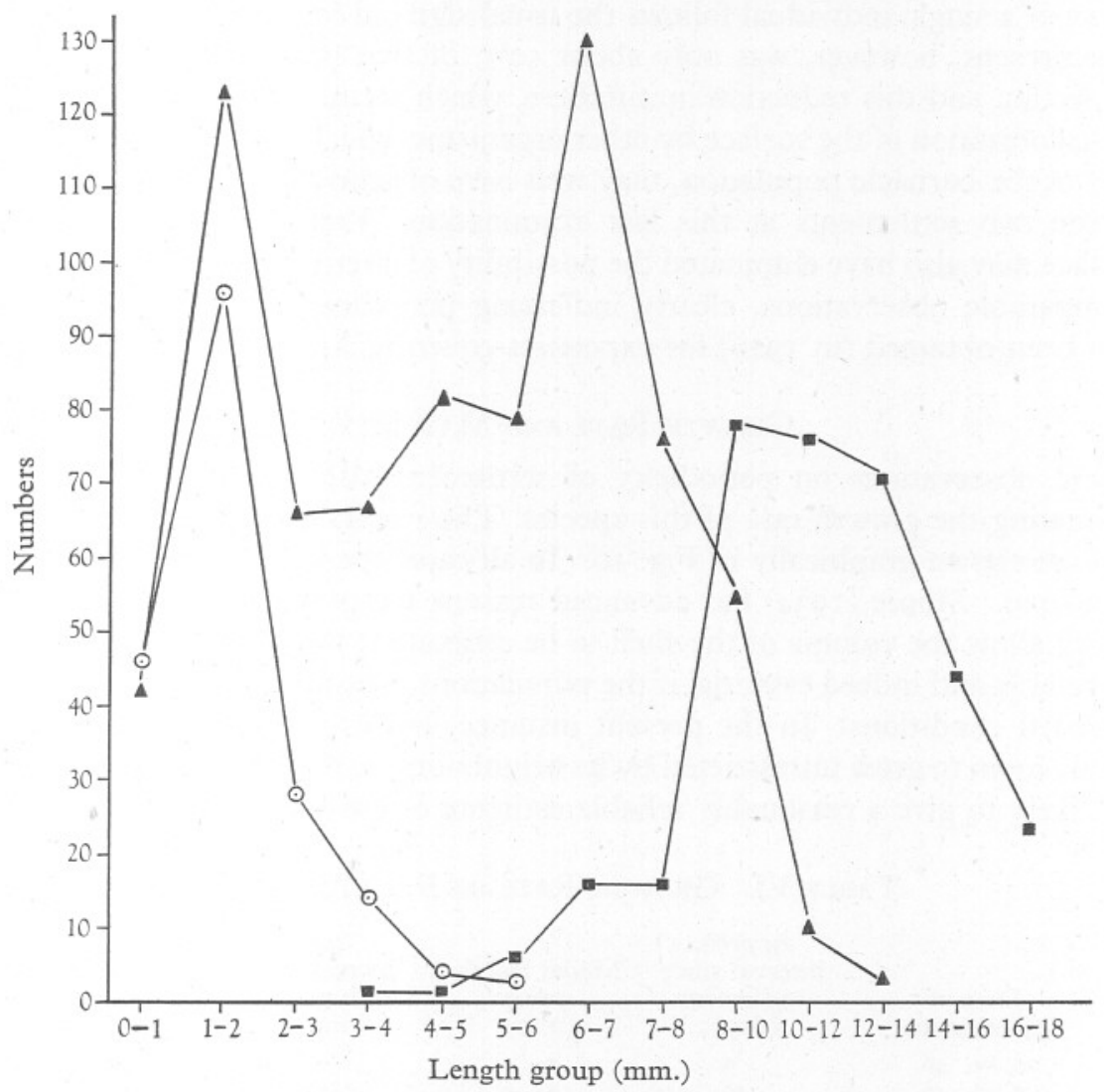

Fig. 9. Analyses of populations of Balanus crenatus, I943. - -26 June; - $\mathbf{A}-24$ July; - - I4 Sept.

The characteristic feature of the settlement of $B$. crenatus is its periodicity. Fig. 9 gives records of the measurements made on a population of $B$. crenatus which settled on a surface first exposed towards the end of May I943. 32 days later I9I $B$. crenatus had settled on one face (4 sq.ft.), their modal length group ( $\mathrm{I}-2 \mathrm{~mm}$.) indicating that settlement had occurred shortly before the surface was examined. Roughly 2 months after immersion the population had risen to 735 over the same face and the length-group distribution was distinctly bi-modal; one mode occurring again in the $\mathrm{I}-2 \mathrm{~mm}$. basal length 
group (and therefore representing a recent settlement) and the other (presumably representing the June settlement) in the 6-7 $\mathrm{mm}$. group. Just over 2 months later, the surface was again examined and the population again proved to be uni-modal, with a rather ill-defined mode in the 8-10 $\mathrm{mm}$. group. This single mode could have been produced by the merging of the two settlements so evident at the earlier inspection if it is assumed that the growth curve of a single individual follows the usual sigmoid form. The total population present, however, was only about $50 \%$ of that present at the previous inspection and this reduction in numbers, which seemed to have been due to the colonization of the surface by other organisms, which smothered and killed part of the barnacle population, may well have obscured the true relationship of the two settlements at this last examination. Prior colonization of the surface may also have eliminated the possibility of a settlement during August. Comparable observations, clearly indicating periodicity of settlement, have also been obtained (in 1946) for exposures covering April and May.

\section{Growth Rate and Maturity}

These observations on periodicity of settlement also provide a means of estimating the growth rate of this species. The results are given in Table VI and are shown graphically in Fig. IO. In all cases the length of the basis was measured. Moore (1934) has advanced reasons for preferring measurements which allow the volume of the shell to be estimated; this estimation is clearly preferable and indeed essential if the populations measured are growing under crowded conditions. In the present instance, however, each individual had ample room to grow unrestricted by its neighbours, so that basis measurements are likely to give a reasonably reliable estimate of growth rate.

\section{Table VI. Growth Rate of B. cREnatus}

\begin{tabular}{|c|c|c|c|c|}
\hline $\begin{array}{l}\text { Date of } \\
\text { examination }\end{array}$ & $\begin{array}{l}\text { Approx. } \\
\text { interval since } \\
\text { settlement } \\
\text { (days) }\end{array}$ & $\begin{array}{l}\text { Modal length } \\
\text { group } \\
\text { (mm.) }\end{array}$ & $\begin{array}{c}\text { Mean } \\
\text { increase in } \\
\text { length per day } \\
(\mathrm{mm} .)\end{array}$ & $\begin{array}{l}\text { Maximum length } \\
\text { group } \\
\text { (mm.) }\end{array}$ \\
\hline $\begin{array}{r}\text { 3o. iv. } 46 \\
\text { 5. vi. } 46 \\
\text { 2. vii. } 46\end{array}$ & $\begin{array}{r}5 \\
40 \\
67\end{array}$ & $\begin{array}{r}0-1 \\
5-6 \\
10-12\end{array}$ & $\begin{array}{l}- \\
0 \cdot 14 \\
0.20\end{array}$ & $\frac{-}{14-16}$ \\
\hline $\begin{array}{l}\text { 26. vi. } 43 \\
\text { 24. vii. } 43 \\
\text { I4. ix. } 43\end{array}$ & $\begin{array}{l}\text { 10 } \\
39 \\
91\end{array}$ & $\begin{array}{r}\mathrm{I}-2 \\
6-7 \\
\mathrm{IO}-\mathrm{I} 2\end{array}$ & $\begin{array}{l}0.15 \\
0 \cdot 17 \\
0 \cdot 12\end{array}$ & $\frac{Z}{20-22}$ \\
\hline $\begin{array}{l}\text { 25. x. } 46 \\
\text { I7. xii. } 46 \\
\text { 25. i. } 47 \\
\text { 27. ii. } 47 \\
\text { I9. v. } 47 \\
\text { I9. vi. } 47\end{array}$ & $\begin{array}{r}\text { ? } 40 \\
\text { ?93 } \\
\text { ? } 132 \\
\text { ? } 165 \\
\text { ? } 246 \\
\text { ? } 277\end{array}$ & $\begin{array}{r}5-6 \\
6-7 \\
6-7 \\
6-7 \\
10-12 \\
14-16\end{array}$ & $\begin{array}{l}0.14 \\
0.02 \\
0 \\
0 \\
0.06 \\
0.13\end{array}$ & $\begin{array}{l}\bar{Z} \\
\overline{8-10} \\
\text { I8-20 }\end{array}$ \\
\hline
\end{tabular}

Growth evidently takes place steadily through the summer months, but is arrested during the winter. There is no suggestion, for this species, of the 


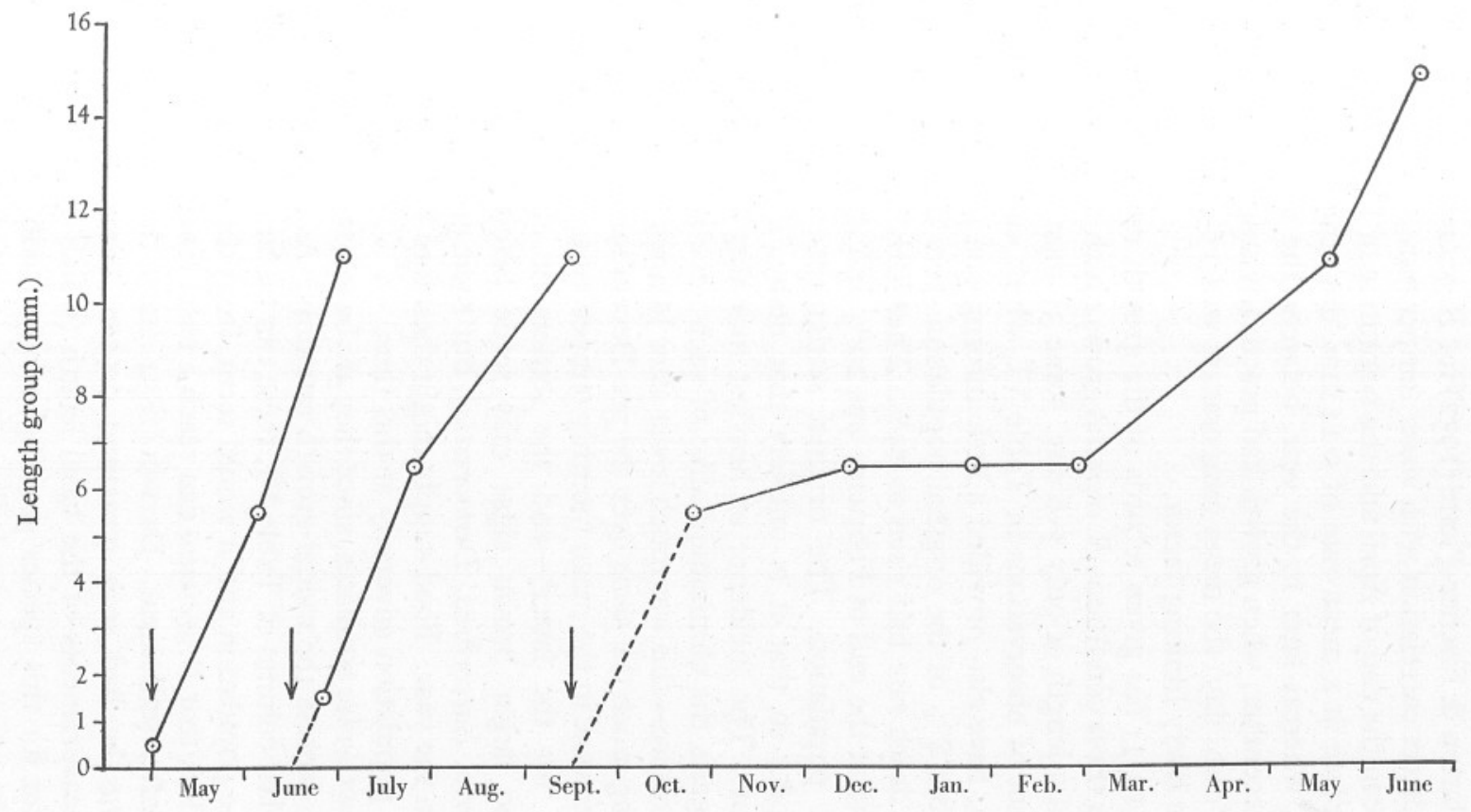

ש્

Fig. Io. Growth rate of Balanus crenatus. The arrows indicate the approximate date of settlement. 
limitation of growth to a short period early in the summer, as has been recorded by Hatton \& Fischer-Piette (1932) for B. balanoides. There is also little sign of any direct correlation with water temperature, for example, during the period between the end of April and the beginning of June 1946, when growth was taking place at a mean rate of $0.14 \mathrm{~mm}$./day, the mean sea temperature was $8.4^{\circ} \mathrm{C}$., whereas later in the year, between the end of October and the middle of December, when growth had practically stopped (a mean increment of only $0.02 \mathrm{~mm}$. day) the mean temperature was $9.6^{\circ} \mathrm{C}$. Food supply would seem a more likely limiting factor.

Topsent (I9II) has given records of the growth rate of B. crenatus on the shore; under these conditions $B$. crenatus grows much more slowly, as the basis had achieved a length of only $5-6 \mathrm{~mm}$. some $3 \frac{1}{2}$ months after settlement.

The last set of observations in Table VI, which cover autumn and winter growth rates, have also provided a little information on winter mortality. By mid-December $8 \%$ of the original population were dead and by the end of January the death rate had risen to $19 \%$. Thereafter mortality was slight, as the death rate at the end of February was $20 \%$ and that in mid-May $21 \%$ of the original population. The original settlement was light (density 230 barnacles/sq.ft.) so that it is unlikely that many, if any, individuals were 'crowded out'. The incidence of heaviest mortality in the period OctoberJanuary suggests the elimination alike of such adverse factors as decrease in water temperature-this was much lower after January, the rate of temperature decrease being much the same over the pre-December and the post-December periods (a decrease in the mean monthly temperature of $3.4^{\circ} \mathrm{C}$. for the former and $3 . \mathrm{I}^{\circ} \mathrm{C}$. for the latter)-and the settlement of other fouling forms. Some of the larger brown algae may settle before the end of January (e.g. Laminaria, Saccorhiza, Desmarestia), but their growth is negligible until much later in the year. Food supply might therefore be the factor most likely to affect the population adversely at this time.

These growth-rate estimates, since they are based on modal length groups of populations, express the modal growth rate only. As is shown by the figures given in the last column of Table VI, these can be far exceeded by a few individuals in the population and it would seem, from the second set of measurements recorded, that $B$. crenatus can reach a basal length of just under $I$ in. in 3-4 months after settlement. Darwin (I854) states that the largest specimens of $B$. crenatus he had seen measured 0.55 in. (roughly $\mathrm{I} 4 \mathrm{~mm}$.) in basal diameter; measurements of the basal length (which closely approximates to basal diameter for this species growing unrestrictedly) of a large number of individual $B$. crenatus made during the present survey indicate that the largest specimens came within the $28-30 \mathrm{~mm}$. length group. As has just been mentioned, 3-4 months' growth can produce a barnacle with a base $20-22 \mathrm{~mm}$. in length and this series of observations has also shown that, given a slightly longer growing period, a basal length of $26-28 \mathrm{~mm}$. can be attained in the year 
of settlement. A specimen of B. crenatus which settles early in April can therefore virtually reach the maximum recorded basal length before the end of the growing period of its year of settlement.

When the first set of growth-rate observations recorded in Table VI were discontinued early in July, the population was examined and the state of development of the ovigerous lamellae determined. The results are shown in Fig. II. Some proportion of all the individuals of basal length greater than 4-5 mm. showed the presence of developing ova in the ovigerous lamellae, and individuals of basal length $\mathrm{I} 2-\mathrm{I} 4 \mathrm{~mm}$. or more all contained developing

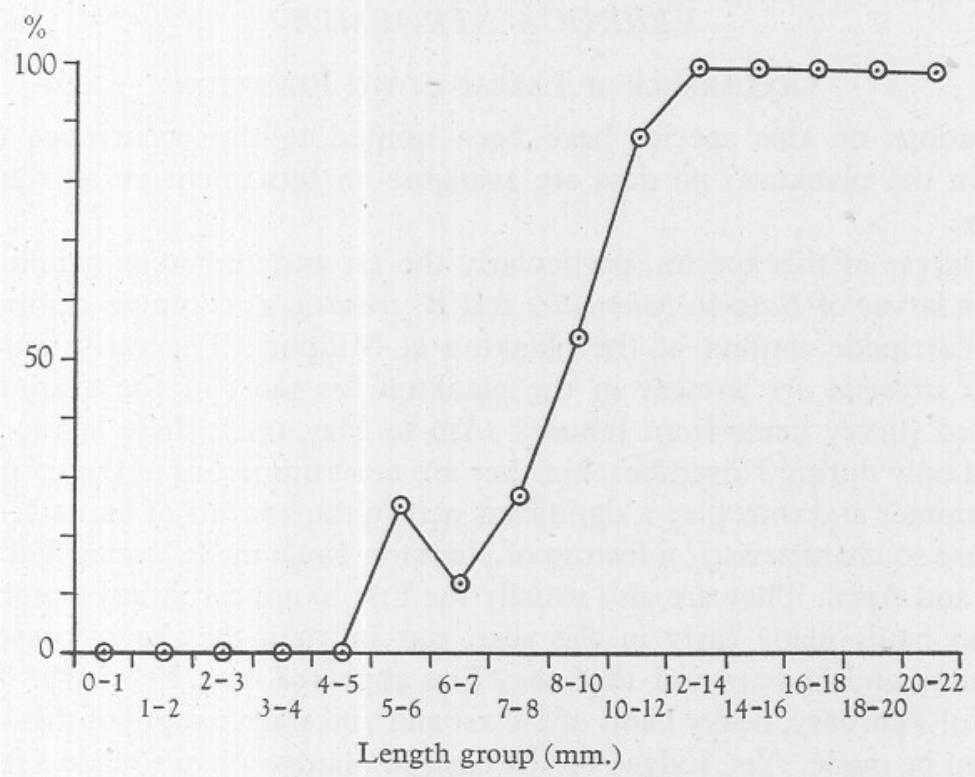

Fig. II. Occurrence of developing ova in young Balanus crenatus, expressed as percentage of individuals containing them.

ova. Most of these ova were in the early stages of development (Stages I or 2, see p. 477) but one individual, of $\mathrm{I} 2-\mathrm{I} 4 \mathrm{~mm}$. basal length, contained larvae ready to hatch. B. crenatus evidently attains maturity a very short time after settlement, as individuals which had settled late in April presumably could themselves liberate larvae during July.

Individuals which settle in the autumn are mature, as perhaps might be expected from the foregoing observation, the following spring. For example, a proportion (roughly $30 \%$ ) of the population which settled in the autumn of I946 (see Table VI) was examined in May I947. $77 \%$ of these individuals contained developing ova at some stage, and of those in this condition roughly half contained larvae ready to hatch. 
Moore (I934) finds that most of the 'lower- and middle-zone (B. balanoides) die in their 3 rd year, but those from the top zone may live for 5 years or more'. Exact data of the length of life of $B$. crenatus are not available, but the impression gained is that the latter species has a shorter life than even the 'lower- and middle-zone' B. balanoides; it seems possible that a B. crenatus which settles in the spring, may die in the autumn of the following year. Present evidence suggests that it spawns twice and possibly three times during this period, once later in the summer of the year of settlement, once the following spring and possibly once again later that year.

\section{VERRUCA STROEMIA}

\section{OcCuRRence of LaRvae in the Plankton}

Observations on this species have been limited to the occurrence of the larvae in the plankton; no data are available on settlement or on the adult barnacle.

The larvae of this species, particularly the Ist and 2nd stage nauplii, rank with the larvae of Balanus balanoides and B. crenatus as common components of the Cirripede content of the plankton at Millport. The early nauplii of Verruca stroemia are present in the plankton for most of the year, e.g. in a detailed survey made from January I946 to May 1947, these larvae lacked a record only during November, but they are most numerous in the spring and early summer and thus play a significant part in the swarms of barnacle larvae which are so characteristic a feature of plankton hauls made during February, March and April. They are also usually the first to appear in any numbers in plankton hauls made early in the year, e.g. in 1944 they were present on 3 February and in 1945 and 1946 they first appeared on 2 February. By the middle of February, heavy hauls of the Ist and 2nd stage nauplii of this species can often be made. Yet, judged on the basis of plankton hauls made a few feet below the surface, these large numbers of Ist and 2nd stage nauplii which appear early in the year are not immediately followed by the appearance of later nauplii or cyprids, as with Balanus balanoides and B. crenatus. Fig. I2, which shows the proportion of $(a)$ the Ist and 2 nd stage nauplii and (b) nauplii from the 3 rd stage onwards (plotted as 3 -day averages) which occurred during the early months of I947, emphasizes this point. From 20 February until I6 March the only stages present were the Ist and 2nd stage nauplii, the later naupliar stages (3rd stage onwards) did not assume any considerable proportions until 6 April, and cyprids did not appear until the period beginning 30 April.

Further, the period between 20 February and I6 March was characterized by a preponderance of Ist stage larvae-during this period nearly 46,000 Ist stage nauplii were recorded, but only just over 9000 2nd stage nauplii. Nilsson-Cantell (I92I) found at Bohuslän, W. Sweden, that the Ist naupliar 
stage occupied about a week, and this prolonged preponderance of Ist stage nauplii in the Clyde plankton suggests that this stage has a longer life period than that of the corresponding stages of $B$. balanoides and $B$. crenatus. In the laboratory, however, the Ist stage nauplius of Verruca stroemia moults to give the 2nd stage within a few hours of hatching.

The general sequence of events just described for 1947 also characterized the planktonic occurrence of the larvae of this species for the other years over which this survey extended. Fig. I3 shows the results obtained in I946. Again, heavy hauls of early larvae were taken early in the year (with a preponderance of Ist stage nauplii, though not quite so marked as in I947), no heavy hauls of late stage nauplii were made until much later and no cyprids were recorded until towards the end of April.

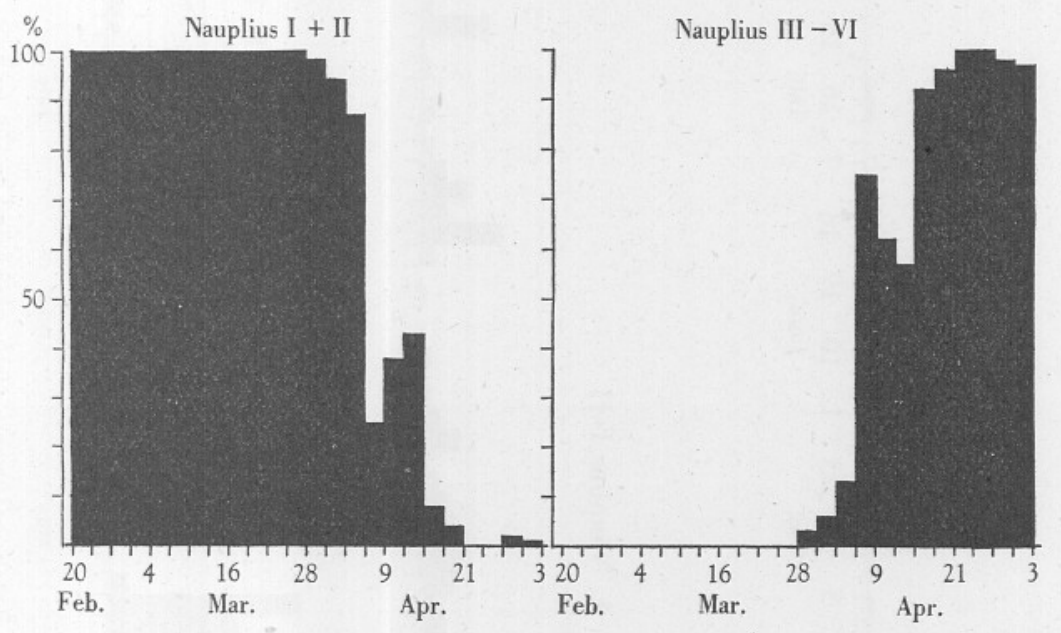

Fig. I2. Occurrence of the larval stages of Verruca stroemia, spring I947. The numbers present, over 3-day periods, of each group of larval stages are expressed as a percentage of the total $V$. stroemia larvae present. (Cyprids were absent except for $2 \%$ during the very last period.)

In the absence of settlement data for Verruca, any suggested explanation of this situation must remain tentative, but there seem two outstanding possibilities. First, it is possible that only the earlier stages of naupliar development occur near the surface, the later-stage nauplii and the cyprids occurring in any numbers only in deeper water, so that the surface records for these stages are misleading. Secondly, it is possible that the record presented by these hauls is substantially correct and that the sequence of larval stages of $V$. stroemia extends over a period which is much longer than that of the two species of Balanus discussed earlier. If the first possibility is correct, it is difficult to see why the periods of abundance of early- and later-stage nauplii should approximate more closely later in the season, whereas if the second possibility is 


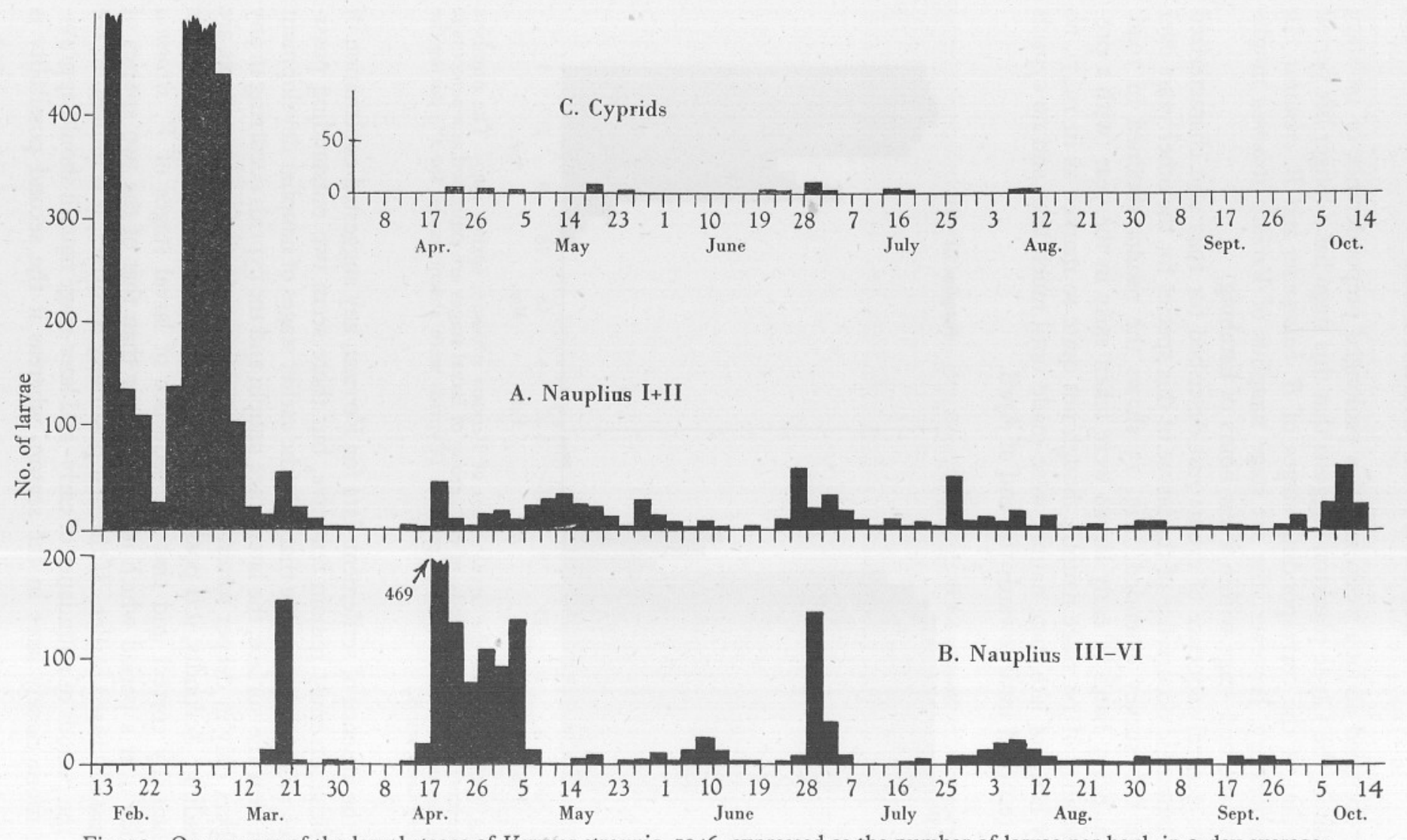

Fig. 13. Occurrence of the larval stages of Verruca stroemia, 1946, expressed as the number of larvae per haul, in 3-day averages. A, nauplii I and II. B, nauplii III-VI. C, cyprids. 
correct a closer correspondence between periods of abundance later in the year might be expected, as rising water temperatures would presumably accelerate larval development. If the larval sequence does take place slowly early in the season, the early-stage larval maximum (Fig. I3 A) beginning on I3 February could be correlated with the later-stage maximum on 18 March (Fig. I3 B) and possibly with the cyprids recorded around 20 April (Fig. I3 C); the early-stage maximum on 28 February with the later-stage maximum beginning on 17 April and the cyprids occurring in the following month, suggesting that the full larval sequence, from hatching to the appearance of the cyprid, takes roughly 2 months at this season. Such links can only be tentatively suggested, particularly as the cyprid stages are never at all common. There are times during the spring and summer when the later-stage nauplii of Verruca are reasonably common (e.g. over 2000 occurred in one haul, made on 30 April I947) but they do not seem to be followed by comparable hauls of the cyprid larva. Perhaps the latter only occurs in numbers in deeper water and, though slow development may be the explanation of the lack of immediate correspondence between the early- and later-stage nauplii of Verruca, surface hauls are not a reliable indication of the abundance of the cyprid larvae.

Though nothing is known of the settlement of this species, it can be predicted, from what is known of the occurrence of the nauplii, that it extends at least over the period April to September and there is a further suggestion that, like that of Balanus crenatus, it may be periodic. Fischer-Piette (I932), however, has recorded the appearance of young Verruca in abundance on the shore on 7 December and he therefore suggests that the approximate time of settlement lies between September and December. This is rather later than the present observations would suggest.

\section{OTHER CIRRIPEDE LARVAE}

The examination of plankton hauls made, for the most part daily, during I946-47 has afforded an opportunity to assess the abundance of other forms. The only larvae that occurred at all regularly were the nauplii of Sacculina (probably S. carcini) and those of Peltogaster paguri. The Peltogaster larvae were at first puzzling, since they differ radically from the figures of the nauplius given by Boschma (I927), notably in possessing a shield-like expansion of the integument, such as Hoek (I909) figures for P. purpureus. They agree, however, with the re-description of the nauplius of $P$. paguri given by Reinhard (I946) ${ }^{1}$; and, furthermore, larvae identical with those found in the plankton have been obtained from specimens of $P$. paguri on Eupagurus bernhardus collected locally.

The records of these two nauplii are given in Table 7. Peltogaster nauplii were present in Io out of the I4 months covered and it would seem possible

${ }_{1}$ Dr. Boschma kindly drew my attention to this paper. 
that they are liberated all the year round. Sacculina larvae, however, proved to be more abundant during the winter months, from November to February or March.

\section{Table VII. Occurrence of the Nauplin of Peltogaster AND SACCULINA}

\begin{tabular}{|c|c|c|}
\hline \multirow[b]{2}{*}{ Month } & \multicolumn{2}{|c|}{ Nauplii recorded } \\
\hline & Peltogaster & Sacculina \\
\hline February (I946) & 4 & 4 \\
\hline $\begin{array}{l}\text { March } \\
\text { April }\end{array}$ & 0 & Io \\
\hline $\begin{array}{l}\text { April } \\
\text { May }\end{array}$ & 0 & 0 \\
\hline May & I2 & 0 \\
\hline June & 4 & 0 \\
\hline July & I9 & I \\
\hline August & 4 & o \\
\hline September & 2 & 0 \\
\hline October & 0 & 5 \\
\hline November & 0 & 33 \\
\hline December & 6 & 37 \\
\hline January (I947) & 8 & 24 \\
\hline February & 29 & 34 \\
\hline March & IO & 0 \\
\hline
\end{tabular}

It is of interest to note that these records of the occurrence of Sacculina nauplii in the plankton confirm in part the conclusions drawn by Foxon (I940) about the breeding season of this parasite in the Clyde.

\section{DISCUSSION}

The descriptions given earlier in this paper of the seasonal occurrence of barnacle larvae in the plankton have clearly indicated their abundance during the months of February, March and April. Tables VIII and IX below set out the average hauls of barnacle larvae per day, for each month of the year, based on the records of this 4-year survey.

In both tables a dash indicates that no hauls were made during that particular month.

The sequence of larvae during the spring outburst is similar year by year. Early-stage nauplii of Verruca stroemia and early-stage nauplii of Balanus crenatus are the first to appear, usually during the latter part of February and early in March. Early-stage nauplii of B. balanoides first appear early in March and reach a maximum towards the middle of that month; the second half of March is characterized by the presence of large numbers of later-stage nauplii of $B$. crenatus and B. balanoides sometimes (e.g. in I946) accompanied by smaller numbers of later-stage nauplii of Verruca stroemia. The end of March or the beginning of April sees the appearance of the first cyprid stages and during the first half of the latter month the cyprid of Balanus balanoides tends to predominate. During the second half of April the numbers of Cirripede 
larvae usually decrease and by the end of that month, or early in May, they are reduced to the more modest proportions which they maintain, in general, for the rest of the summer. The numbers recorded after the end of October are negligible. Figs. I4-I7 show the details of the records of the nauplii and cyprids of $B$. balanoides, $B$. crenatus and Verruca stroemia during the spring outburst in 2 successive years, I946 and I 947.

\section{Table VIII. All Cirripede Naupli Month by Month}

Expressed as the average number per daily haul

\begin{tabular}{|c|c|c|c|c|}
\hline \multirow[b]{2}{*}{ Month } & \multicolumn{4}{|c|}{ Year } \\
\hline & I944 & I945 & 1946 & 1947 \\
\hline January & - & 0 & 0 & I \\
\hline February & I716 & $2 \mathrm{I}$ & 607 & 419 \\
\hline March & 2846 & 274 & 2034 & 13644 \\
\hline April & 515 & 52 & 725 & 12199 \\
\hline May & 7 & - & 136 & . \\
\hline June & - & - & 50 & . \\
\hline July & - & - & 25 & . \\
\hline August & - & - & $2 \mathrm{I}$ & \\
\hline September & - & - & 9 & . \\
\hline October & - & - & 30 & . \\
\hline November & - & - & 0 & . \\
\hline December & - & - & I & . \\
\hline
\end{tabular}

Table IX. All Cyprid Larvae Month by Month

Expressed as the average number per daily haul

\begin{tabular}{|c|c|c|c|c|}
\hline \multirow[b]{2}{*}{ Month } & \multicolumn{4}{|c|}{ Year } \\
\hline & I944 & I945 & I946 & I947 \\
\hline January & - & 0 & 0 & 0 \\
\hline February & 0 & $\circ$ & 0 & 0 \\
\hline March & I5 & 5 & I & 22 \\
\hline April & I $49 \mathrm{I}$ & 137 & IIO & 2918 \\
\hline May & 35 & - & 68 & . \\
\hline June & - & - & I7 & \\
\hline July & - & - & 28 & . \\
\hline August & - & - & I7 & . \\
\hline September & - & - & I & . \\
\hline October & - & - & 3 & . \\
\hline November & 一 & - & 0 & - \\
\hline December & - & - & o & . \\
\hline
\end{tabular}

The figures given in Tables VIII and IX also emphasize the enormous variations that can occur from year to year. For detailed quantitative comparisons, the fishing methods used in this survey were crude, but even so, a difference such as that between the average catch of all stages of all Cirripede nauplii for March I945 (274 nauplii) and that recorded for the corresponding month 2 years later (13,644 nauplii) - the latter practically fifty times the former-is great enough to be significant. Johnstone, Scott \& Chadwick (1924) give figures for Balanus balanoides nauplii and cyprids for the period 
1907-20, and it is of interest to find that even greater variations appear in their records, e.g. more than two thousand times the number of nauplii were recorded in March 1912 than in March 1907.

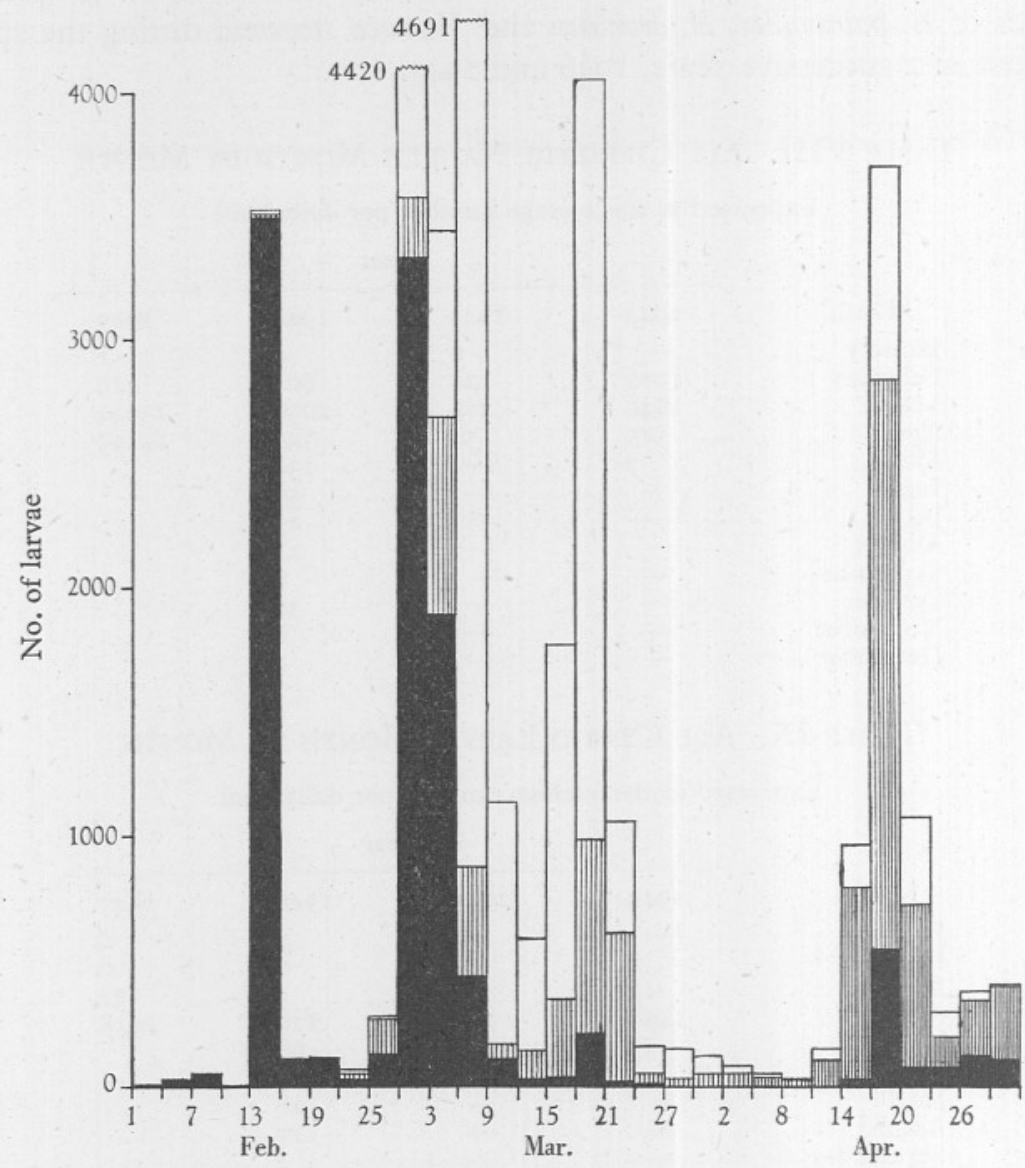

Fig. I4. Occurrence of Cirripede nauplii, Feb.-Apr. I946. The shaded areas within each histogram indicate the numbers of the larvae of Verruca stroemia; the vertically hatched areas the numbers of Balanus crenatus larvae; the remaining areas the numbers of $B$. balanoides larvae.

Direct comparisons between the records obtained in the present survey and those obtained by Johnstone, Scott \& Chadwick (1924) are impossible since fishing conditions were entirely different in the two surveys. One point, however, seems worthy of mention. Johnstone, Scott \& Chadwick (loc. cit. p. 66) drew attention to the great discrepancy between the numbers of nauplii and the numbers of cyprids caught, and attributed this to the destruction of the nauplii during their period of development and to the dispersal of the swarms. 
consisting of a recent settlement-probably early August-and an earlier settlement, probably early July.

From this table it is evident that settlement has been heavier some distance below the water-line; $75 \%$ of the settlement was limited to depths greater than $5 \mathrm{ft}$. It should, however, be emphasized that these data have been obtained from a floating object, since the surface was immersed from a raft.

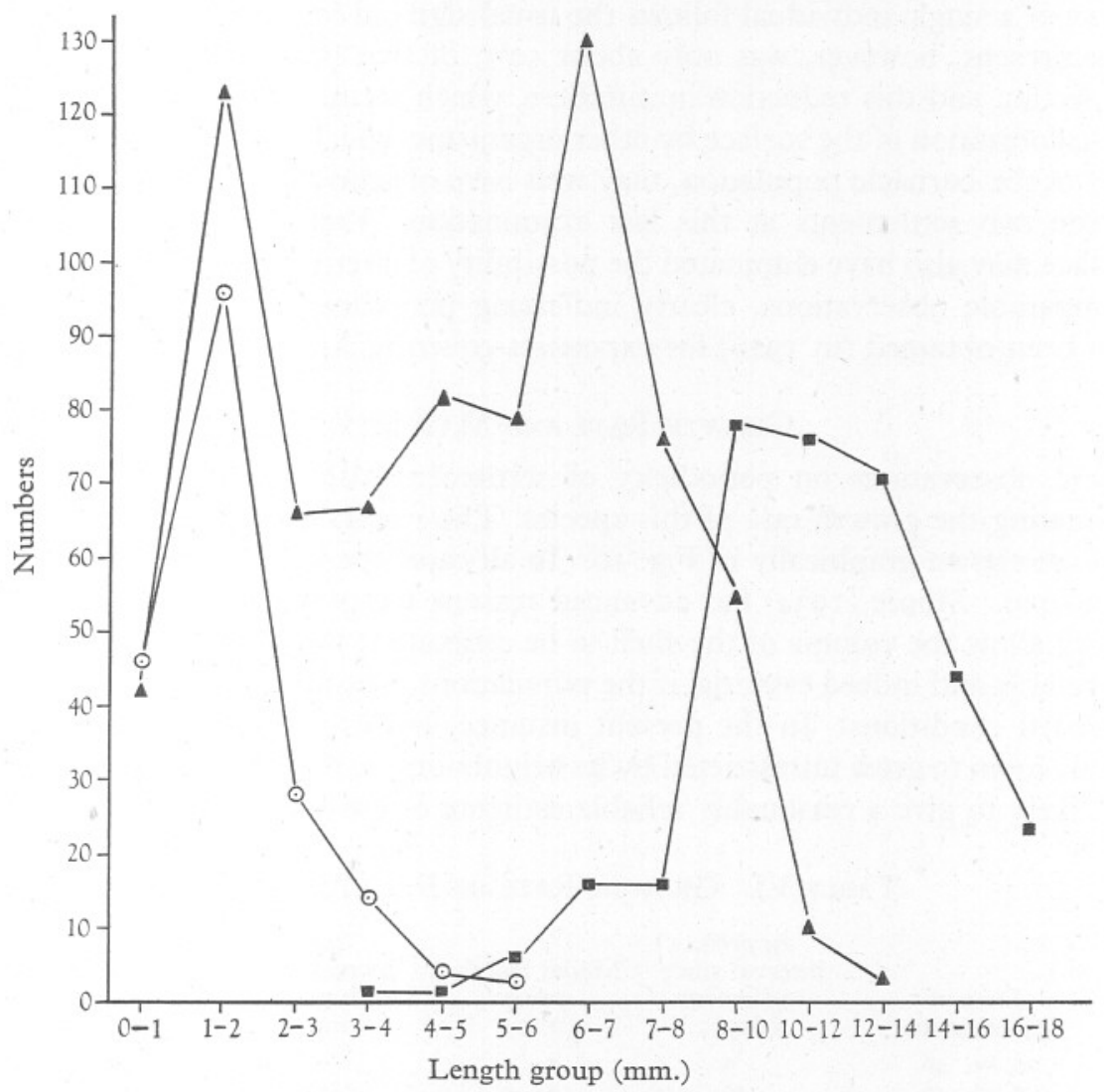

Fig. 9. Analyses of populations of Balanus crenatus, I943. - -26 June; - $\mathbf{A}-24$ July; - - I4 Sept.

The characteristic feature of the settlement of $B$. crenatus is its periodicity. Fig. 9 gives records of the measurements made on a population of $B$. crenatus which settled on a surface first exposed towards the end of May I943. 32 days later I9I $B$. crenatus had settled on one face (4 sq.ft.), their modal length group ( $\mathrm{I}-2 \mathrm{~mm}$.) indicating that settlement had occurred shortly before the surface was examined. Roughly 2 months after immersion the population had risen to 735 over the same face and the length-group distribution was distinctly bi-modal; one mode occurring again in the $\mathrm{I}-2 \mathrm{~mm}$. basal length 
group (and therefore representing a recent settlement) and the other (presumably representing the June settlement) in the 6-7 $\mathrm{mm}$. group. Just over 2 months later, the surface was again examined and the population again proved to be uni-modal, with a rather ill-defined mode in the 8-10 $\mathrm{mm}$. group. This single mode could have been produced by the merging of the two settlements so evident at the earlier inspection if it is assumed that the growth curve of a single individual follows the usual sigmoid form. The total population present, however, was only about $50 \%$ of that present at the previous inspection and this reduction in numbers, which seemed to have been due to the colonization of the surface by other organisms, which smothered and killed part of the barnacle population, may well have obscured the true relationship of the two settlements at this last examination. Prior colonization of the surface may also have eliminated the possibility of a settlement during August. Comparable observations, clearly indicating periodicity of settlement, have also been obtained (in 1946) for exposures covering April and May.

\section{Growth Rate and Maturity}

These observations on periodicity of settlement also provide a means of estimating the growth rate of this species. The results are given in Table VI and are shown graphically in Fig. IO. In all cases the length of the basis was measured. Moore (1934) has advanced reasons for preferring measurements which allow the volume of the shell to be estimated; this estimation is clearly preferable and indeed essential if the populations measured are growing under crowded conditions. In the present instance, however, each individual had ample room to grow unrestricted by its neighbours, so that basis measurements are likely to give a reasonably reliable estimate of growth rate.

\section{Table VI. Growth Rate of B. cREnatus}

\begin{tabular}{|c|c|c|c|c|}
\hline $\begin{array}{l}\text { Date of } \\
\text { examination }\end{array}$ & $\begin{array}{l}\text { Approx. } \\
\text { interval since } \\
\text { settlement } \\
\text { (days) }\end{array}$ & $\begin{array}{l}\text { Modal length } \\
\text { group } \\
\text { (mm.) }\end{array}$ & $\begin{array}{c}\text { Mean } \\
\text { increase in } \\
\text { length per day } \\
(\mathrm{mm} .)\end{array}$ & $\begin{array}{l}\text { Maximum length } \\
\text { group } \\
\text { (mm.) }\end{array}$ \\
\hline $\begin{array}{r}\text { 3o. iv. } 46 \\
\text { 5. vi. } 46 \\
\text { 2. vii. } 46\end{array}$ & $\begin{array}{r}5 \\
40 \\
67\end{array}$ & $\begin{array}{r}0-1 \\
5-6 \\
10-12\end{array}$ & $\begin{array}{l}- \\
0 \cdot 14 \\
0.20\end{array}$ & $\frac{-}{14-16}$ \\
\hline $\begin{array}{l}\text { 26. vi. } 43 \\
\text { 24. vii. } 43 \\
\text { I4. ix. } 43\end{array}$ & $\begin{array}{l}\text { 10 } \\
39 \\
91\end{array}$ & $\begin{array}{r}\mathrm{I}-2 \\
6-7 \\
\mathrm{IO}-\mathrm{I} 2\end{array}$ & $\begin{array}{l}0.15 \\
0 \cdot 17 \\
0 \cdot 12\end{array}$ & $\frac{Z}{20-22}$ \\
\hline $\begin{array}{l}\text { 25. x. } 46 \\
\text { I7. xii. } 46 \\
\text { 25. i. } 47 \\
\text { 27. ii. } 47 \\
\text { I9. v. } 47 \\
\text { I9. vi. } 47\end{array}$ & $\begin{array}{r}\text { ? } 40 \\
\text { ?93 } \\
\text { ? } 132 \\
\text { ? } 165 \\
\text { ? } 246 \\
\text { ? } 277\end{array}$ & $\begin{array}{r}5-6 \\
6-7 \\
6-7 \\
6-7 \\
10-12 \\
14-16\end{array}$ & $\begin{array}{l}0.14 \\
0.02 \\
0 \\
0 \\
0.06 \\
0.13\end{array}$ & $\begin{array}{l}\bar{Z} \\
\overline{8-10} \\
\text { I8-20 }\end{array}$ \\
\hline
\end{tabular}

Growth evidently takes place steadily through the summer months, but is arrested during the winter. There is no suggestion, for this species, of the 


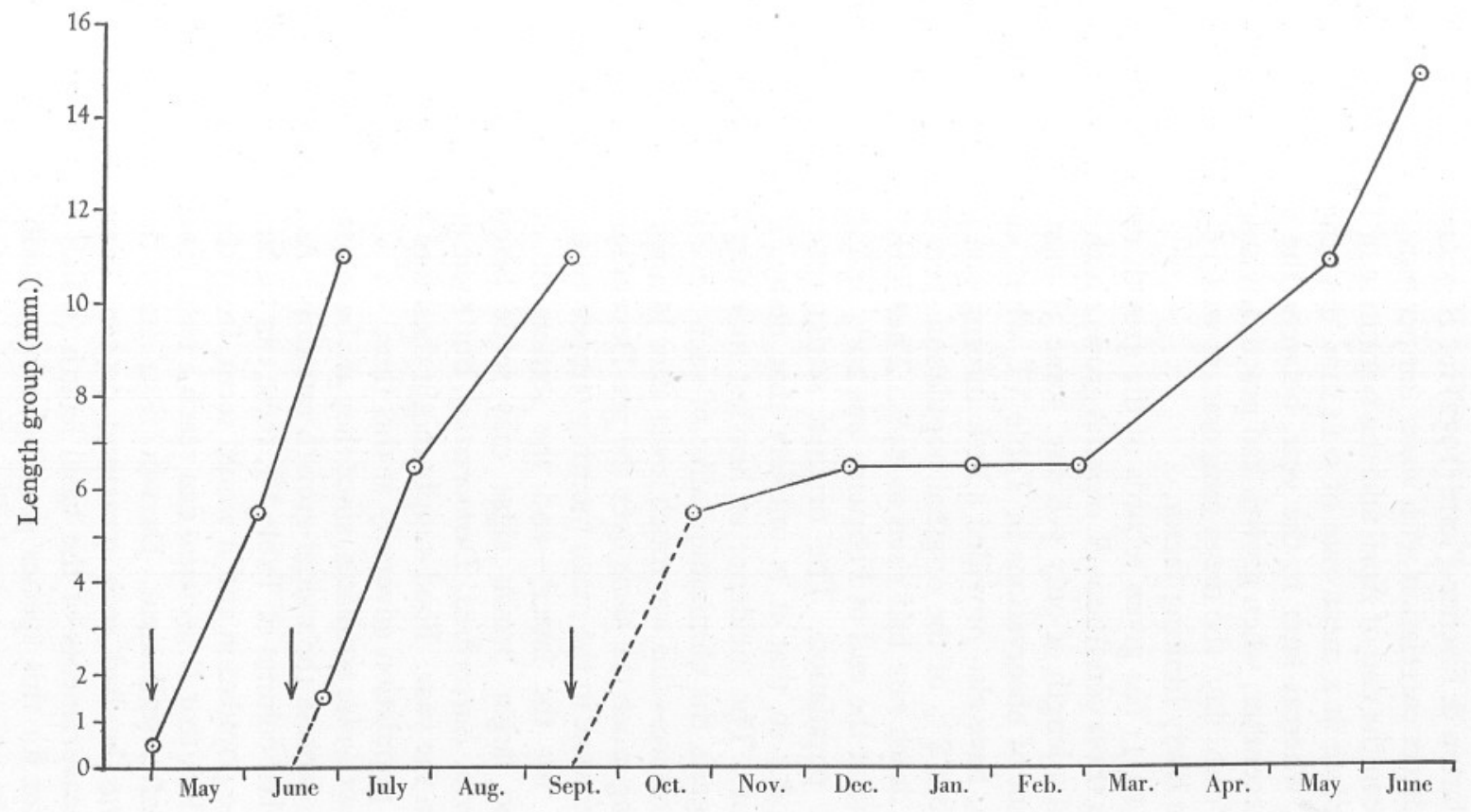

ש્

Fig. Io. Growth rate of Balanus crenatus. The arrows indicate the approximate date of settlement. 
limitation of growth to a short period early in the summer, as has been recorded by Hatton \& Fischer-Piette (1932) for B. balanoides. There is also little sign of any direct correlation with water temperature, for example, during the period between the end of April and the beginning of June 1946, when growth was taking place at a mean rate of $0.14 \mathrm{~mm}$./day, the mean sea temperature was $8.4^{\circ} \mathrm{C}$., whereas later in the year, between the end of October and the middle of December, when growth had practically stopped (a mean increment of only $0.02 \mathrm{~mm}$. day) the mean temperature was $9.6^{\circ} \mathrm{C}$. Food supply would seem a more likely limiting factor.

Topsent (I9II) has given records of the growth rate of B. crenatus on the shore; under these conditions $B$. crenatus grows much more slowly, as the basis had achieved a length of only $5-6 \mathrm{~mm}$. some $3 \frac{1}{2}$ months after settlement.

The last set of observations in Table VI, which cover autumn and winter growth rates, have also provided a little information on winter mortality. By mid-December $8 \%$ of the original population were dead and by the end of January the death rate had risen to $19 \%$. Thereafter mortality was slight, as the death rate at the end of February was $20 \%$ and that in mid-May $21 \%$ of the original population. The original settlement was light (density 230 barnacles/sq.ft.) so that it is unlikely that many, if any, individuals were 'crowded out'. The incidence of heaviest mortality in the period OctoberJanuary suggests the elimination alike of such adverse factors as decrease in water temperature-this was much lower after January, the rate of temperature decrease being much the same over the pre-December and the post-December periods (a decrease in the mean monthly temperature of $3.4^{\circ} \mathrm{C}$. for the former and $3 . \mathrm{I}^{\circ} \mathrm{C}$. for the latter)-and the settlement of other fouling forms. Some of the larger brown algae may settle before the end of January (e.g. Laminaria, Saccorhiza, Desmarestia), but their growth is negligible until much later in the year. Food supply might therefore be the factor most likely to affect the population adversely at this time.

These growth-rate estimates, since they are based on modal length groups of populations, express the modal growth rate only. As is shown by the figures given in the last column of Table VI, these can be far exceeded by a few individuals in the population and it would seem, from the second set of measurements recorded, that $B$. crenatus can reach a basal length of just under $I$ in. in 3-4 months after settlement. Darwin (I854) states that the largest specimens of $B$. crenatus he had seen measured 0.55 in. (roughly $\mathrm{I} 4 \mathrm{~mm}$.) in basal diameter; measurements of the basal length (which closely approximates to basal diameter for this species growing unrestrictedly) of a large number of individual $B$. crenatus made during the present survey indicate that the largest specimens came within the $28-30 \mathrm{~mm}$. length group. As has just been mentioned, 3-4 months' growth can produce a barnacle with a base $20-22 \mathrm{~mm}$. in length and this series of observations has also shown that, given a slightly longer growing period, a basal length of $26-28 \mathrm{~mm}$. can be attained in the year 
of settlement. A specimen of B. crenatus which settles early in April can therefore virtually reach the maximum recorded basal length before the end of the growing period of its year of settlement.

When the first set of growth-rate observations recorded in Table VI were discontinued early in July, the population was examined and the state of development of the ovigerous lamellae determined. The results are shown in Fig. II. Some proportion of all the individuals of basal length greater than 4-5 mm. showed the presence of developing ova in the ovigerous lamellae, and individuals of basal length $\mathrm{I} 2-\mathrm{I} 4 \mathrm{~mm}$. or more all contained developing

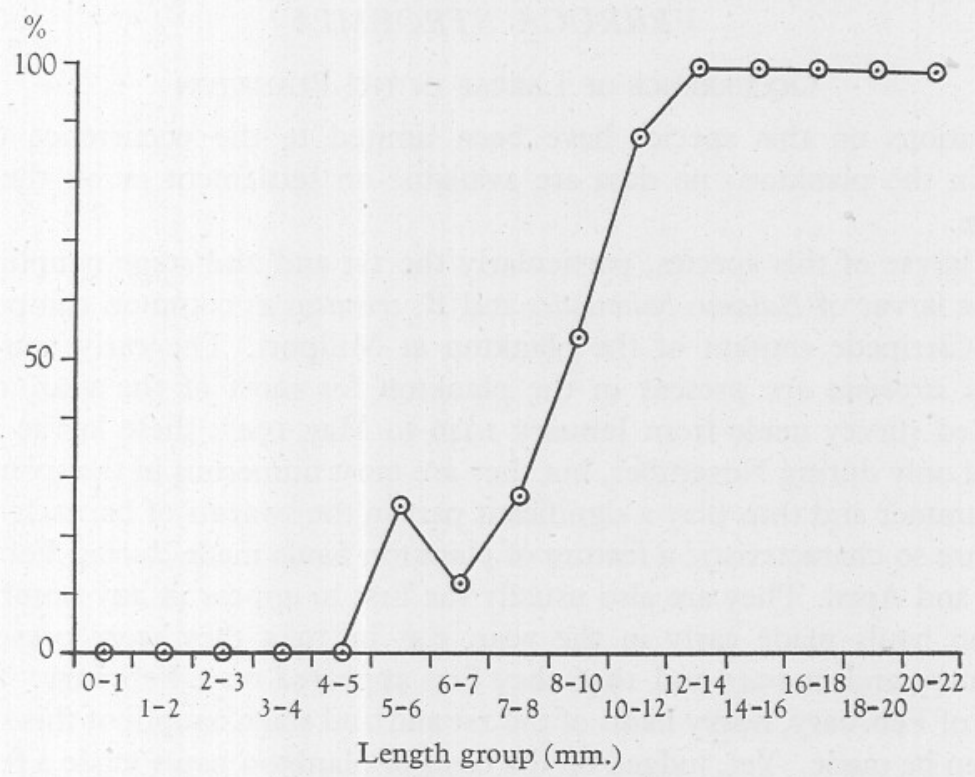

Fig. II. Occurrence of developing ova in young Balanus crenatus, expressed as percentage of individuals containing them.

ova. Most of these ova were in the early stages of development (Stages I or 2, see p. 477) but one individual, of $\mathrm{I} 2-\mathrm{I} 4 \mathrm{~mm}$. basal length, contained larvae ready to hatch. B. crenatus evidently attains maturity a very short time after settlement, as individuals which had settled late in April presumably could themselves liberate larvae during July.

Individuals which settle in the autumn are mature, as perhaps might be expected from the foregoing observation, the following spring. For example, a proportion (roughly $30 \%$ ) of the population which settled in the autumn of I946 (see Table VI) was examined in May I947. $77 \%$ of these individuals contained developing ova at some stage, and of those in this condition roughly half contained larvae ready to hatch. 
Moore (I934) finds that most of the 'lower- and middle-zone (B. balanoides) die in their 3 rd year, but those from the top zone may live for 5 years or more'. Exact data of the length of life of $B$. crenatus are not available, but the impression gained is that the latter species has a shorter life than even the 'lower- and middle-zone' B. balanoides; it seems possible that a B. crenatus which settles in the spring, may die in the autumn of the following year. Present evidence suggests that it spawns twice and possibly three times during this period, once later in the summer of the year of settlement, once the following spring and possibly once again later that year.

\section{VERRUCA STROEMIA}

\section{OcCuRRence of LaRvae in the Plankton}

Observations on this species have been limited to the occurrence of the larvae in the plankton; no data are available on settlement or on the adult barnacle.

The larvae of this species, particularly the Ist and 2nd stage nauplii, rank with the larvae of Balanus balanoides and B. crenatus as common components of the Cirripede content of the plankton at Millport. The early nauplii of Verruca stroemia are present in the plankton for most of the year, e.g. in a detailed survey made from January I946 to May 1947, these larvae lacked a record only during November, but they are most numerous in the spring and early summer and thus play a significant part in the swarms of barnacle larvae which are so characteristic a feature of plankton hauls made during February, March and April. They are also usually the first to appear in any numbers in plankton hauls made early in the year, e.g. in 1944 they were present on 3 February and in 1945 and 1946 they first appeared on 2 February. By the middle of February, heavy hauls of the Ist and 2nd stage nauplii of this species can often be made. Yet, judged on the basis of plankton hauls made a few feet below the surface, these large numbers of Ist and 2nd stage nauplii which appear early in the year are not immediately followed by the appearance of later nauplii or cyprids, as with Balanus balanoides and B. crenatus. Fig. I2, which shows the proportion of $(a)$ the Ist and 2 nd stage nauplii and (b) nauplii from the 3 rd stage onwards (plotted as 3 -day averages) which occurred during the early months of I947, emphasizes this point. From 20 February until I6 March the only stages present were the Ist and 2nd stage nauplii, the later naupliar stages (3rd stage onwards) did not assume any considerable proportions until 6 April, and cyprids did not appear until the period beginning 30 April.

Further, the period between 20 February and I6 March was characterized by a preponderance of Ist stage larvae-during this period nearly 46,000 Ist stage nauplii were recorded, but only just over 9000 2nd stage nauplii. Nilsson-Cantell (I92I) found at Bohuslän, W. Sweden, that the Ist naupliar 
stage occupied about a week, and this prolonged preponderance of Ist stage nauplii in the Clyde plankton suggests that this stage has a longer life period than that of the corresponding stages of $B$. balanoides and $B$. crenatus. In the laboratory, however, the Ist stage nauplius of Verruca stroemia moults to give the 2nd stage within a few hours of hatching.

The general sequence of events just described for 1947 also characterized the planktonic occurrence of the larvae of this species for the other years over which this survey extended. Fig. I3 shows the results obtained in I946. Again, heavy hauls of early larvae were taken early in the year (with a preponderance of Ist stage nauplii, though not quite so marked as in I947), no heavy hauls of late stage nauplii were made until much later and no cyprids were recorded until towards the end of April.

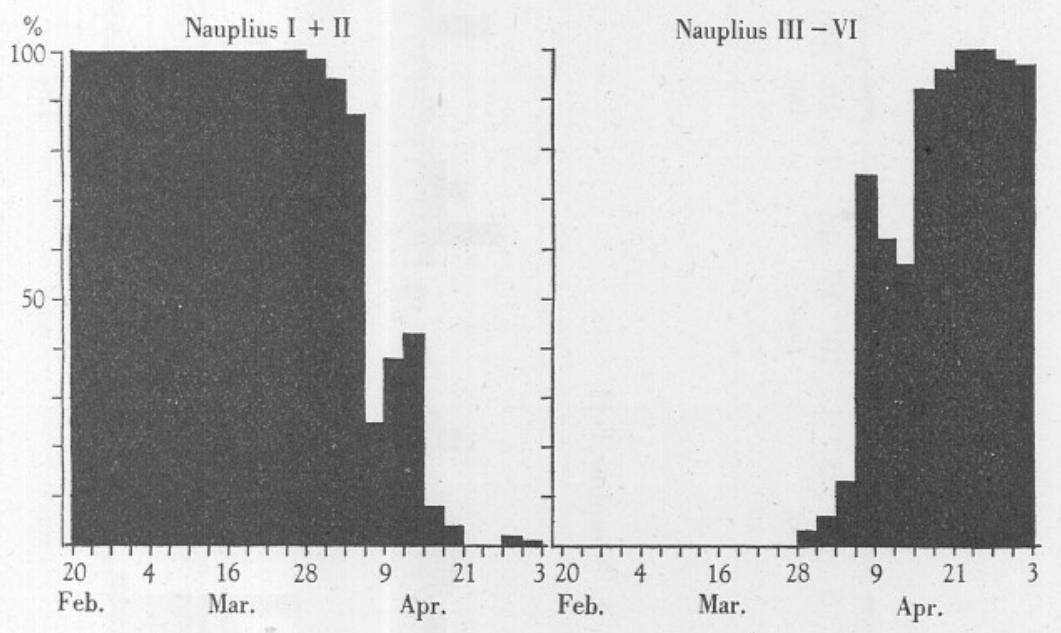

Fig. I2. Occurrence of the larval stages of Verruca stroemia, spring I947. The numbers present, over 3-day periods, of each group of larval stages are expressed as a percentage of the total $V$. stroemia larvae present. (Cyprids were absent except for $2 \%$ during the very last period.)

In the absence of settlement data for Verruca, any suggested explanation of this situation must remain tentative, but there seem two outstanding possibilities. First, it is possible that only the earlier stages of naupliar development occur near the surface, the later-stage nauplii and the cyprids occurring in any numbers only in deeper water, so that the surface records for these stages are misleading. Secondly, it is possible that the record presented by these hauls is substantially correct and that the sequence of larval stages of $V$. stroemia extends over a period which is much longer than that of the two species of Balanus discussed earlier. If the first possibility is correct, it is difficult to see why the periods of abundance of early- and later-stage nauplii should approximate more closely later in the season, whereas if the second possibility is 


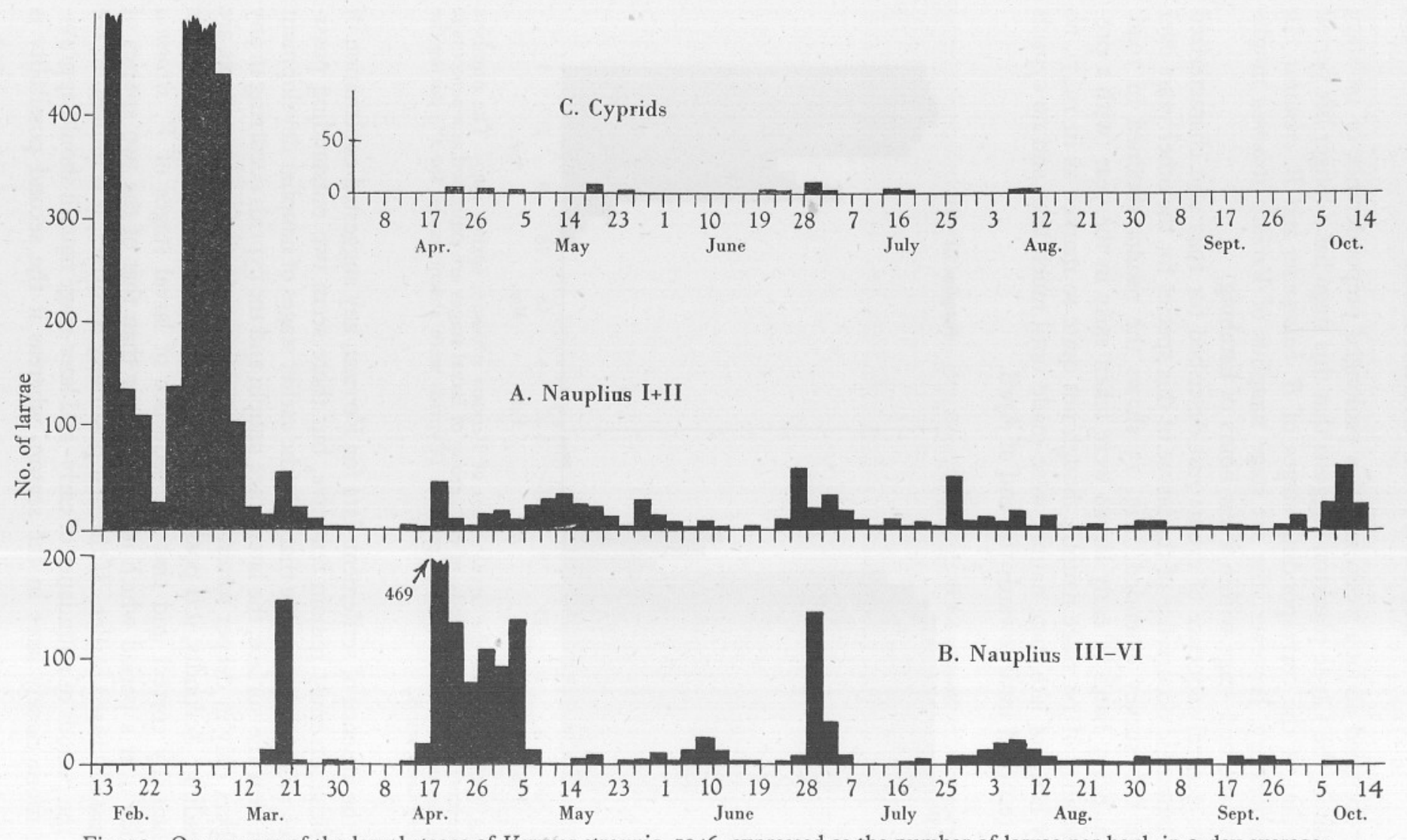

Fig. 13. Occurrence of the larval stages of Verruca stroemia, 1946, expressed as the number of larvae per haul, in 3-day averages. A, nauplii I and II. B, nauplii III-VI. C, cyprids. 
correct a closer correspondence between periods of abundance later in the year might be expected, as rising water temperatures would presumably accelerate larval development. If the larval sequence does take place slowly early in the season, the early-stage larval maximum (Fig. I3 A) beginning on I3 February could be correlated with the later-stage maximum on 18 March (Fig. I3 B) and possibly with the cyprids recorded around 20 April (Fig. I3 C); the early-stage maximum on 28 February with the later-stage maximum beginning on 17 April and the cyprids occurring in the following month, suggesting that the full larval sequence, from hatching to the appearance of the cyprid, takes roughly 2 months at this season. Such links can only be tentatively suggested, particularly as the cyprid stages are never at all common. There are times during the spring and summer when the later-stage nauplii of Verruca are reasonably common (e.g. over 2000 occurred in one haul, made on 30 April I947) but they do not seem to be followed by comparable hauls of the cyprid larva. Perhaps the latter only occurs in numbers in deeper water and, though slow development may be the explanation of the lack of immediate correspondence between the early- and later-stage nauplii of Verruca, surface hauls are not a reliable indication of the abundance of the cyprid larvae.

Though nothing is known of the settlement of this species, it can be predicted, from what is known of the occurrence of the nauplii, that it extends at least over the period April to September and there is a further suggestion that, like that of Balanus crenatus, it may be periodic. Fischer-Piette (I932), however, has recorded the appearance of young Verruca in abundance on the shore on 7 December and he therefore suggests that the approximate time of settlement lies between September and December. This is rather later than the present observations would suggest.

\section{OTHER CIRRIPEDE LARVAE}

The examination of plankton hauls made, for the most part daily, during I946-47 has afforded an opportunity to assess the abundance of other forms. The only larvae that occurred at all regularly were the nauplii of Sacculina (probably S. carcini) and those of Peltogaster paguri. The Peltogaster larvae were at first puzzling, since they differ radically from the figures of the nauplius given by Boschma (I927), notably in possessing a shield-like expansion of the integument, such as Hoek (I909) figures for P. purpureus. They agree, however, with the re-description of the nauplius of $P$. paguri given by Reinhard (I946) ${ }^{1}$; and, furthermore, larvae identical with those found in the plankton have been obtained from specimens of $P$. paguri on Eupagurus bernhardus collected locally.

The records of these two nauplii are given in Table 7. Peltogaster nauplii were present in Io out of the I4 months covered and it would seem possible

${ }_{1}$ Dr. Boschma kindly drew my attention to this paper. 
that they are liberated all the year round. Sacculina larvae, however, proved to be more abundant during the winter months, from November to February or March.

\section{Table VII. Occurrence of the Nauplin of Peltogaster AND SACCULINA}

\begin{tabular}{|c|c|c|}
\hline \multirow[b]{2}{*}{ Month } & \multicolumn{2}{|c|}{ Nauplii recorded } \\
\hline & Peltogaster & Sacculina \\
\hline February (I946) & 4 & 4 \\
\hline $\begin{array}{l}\text { March } \\
\text { April }\end{array}$ & 0 & Io \\
\hline $\begin{array}{l}\text { April } \\
\text { May }\end{array}$ & 0 & 0 \\
\hline May & I2 & 0 \\
\hline June & 4 & 0 \\
\hline July & I9 & I \\
\hline August & 4 & o \\
\hline September & 2 & 0 \\
\hline October & 0 & 5 \\
\hline November & 0 & 33 \\
\hline December & 6 & 37 \\
\hline January (I947) & 8 & 24 \\
\hline February & 29 & 34 \\
\hline March & IO & 0 \\
\hline
\end{tabular}

It is of interest to note that these records of the occurrence of Sacculina nauplii in the plankton confirm in part the conclusions drawn by Foxon (I940) about the breeding season of this parasite in the Clyde.

\section{DISCUSSION}

The descriptions given earlier in this paper of the seasonal occurrence of barnacle larvae in the plankton have clearly indicated their abundance during the months of February, March and April. Tables VIII and IX below set out the average hauls of barnacle larvae per day, for each month of the year, based on the records of this 4-year survey.

In both tables a dash indicates that no hauls were made during that particular month.

The sequence of larvae during the spring outburst is similar year by year. Early-stage nauplii of Verruca stroemia and early-stage nauplii of Balanus crenatus are the first to appear, usually during the latter part of February and early in March. Early-stage nauplii of B. balanoides first appear early in March and reach a maximum towards the middle of that month; the second half of March is characterized by the presence of large numbers of later-stage nauplii of $B$. crenatus and B. balanoides sometimes (e.g. in I946) accompanied by smaller numbers of later-stage nauplii of Verruca stroemia. The end of March or the beginning of April sees the appearance of the first cyprid stages and during the first half of the latter month the cyprid of Balanus balanoides tends to predominate. During the second half of April the numbers of Cirripede 
larvae usually decrease and by the end of that month, or early in May, they are reduced to the more modest proportions which they maintain, in general, for the rest of the summer. The numbers recorded after the end of October are negligible. Figs. I4-I7 show the details of the records of the nauplii and cyprids of $B$. balanoides, $B$. crenatus and Verruca stroemia during the spring outburst in 2 successive years, I946 and I 947.

\section{Table VIII. All Cirripede Naupli Month by Month}

Expressed as the average number per daily haul

\begin{tabular}{|c|c|c|c|c|}
\hline \multirow[b]{2}{*}{ Month } & \multicolumn{4}{|c|}{ Year } \\
\hline & I944 & I945 & 1946 & 1947 \\
\hline January & - & 0 & 0 & I \\
\hline February & I716 & $2 \mathrm{I}$ & 607 & 419 \\
\hline March & 2846 & 274 & 2034 & 13644 \\
\hline April & 515 & 52 & 725 & 12199 \\
\hline May & 7 & - & 136 & . \\
\hline June & - & - & 50 & . \\
\hline July & - & - & 25 & . \\
\hline August & - & - & $2 \mathrm{I}$ & \\
\hline September & - & - & 9 & . \\
\hline October & - & - & 30 & . \\
\hline November & - & - & 0 & . \\
\hline December & - & - & I & . \\
\hline
\end{tabular}

Table IX. All Cyprid Larvae Month by Month

Expressed as the average number per daily haul

\begin{tabular}{|c|c|c|c|c|}
\hline \multirow[b]{2}{*}{ Month } & \multicolumn{4}{|c|}{ Year } \\
\hline & I944 & I945 & I946 & I947 \\
\hline January & - & 0 & 0 & 0 \\
\hline February & 0 & $\circ$ & 0 & 0 \\
\hline March & I5 & 5 & I & 22 \\
\hline April & I $49 \mathrm{I}$ & 137 & IIO & 2918 \\
\hline May & 35 & - & 68 & . \\
\hline June & - & - & I7 & \\
\hline July & - & - & 28 & . \\
\hline August & - & - & I7 & . \\
\hline September & - & - & I & . \\
\hline October & - & - & 3 & . \\
\hline November & 一 & - & 0 & - \\
\hline December & - & - & o & . \\
\hline
\end{tabular}

The figures given in Tables VIII and IX also emphasize the enormous variations that can occur from year to year. For detailed quantitative comparisons, the fishing methods used in this survey were crude, but even so, a difference such as that between the average catch of all stages of all Cirripede nauplii for March I945 (274 nauplii) and that recorded for the corresponding month 2 years later (13,644 nauplii) - the latter practically fifty times the former-is great enough to be significant. Johnstone, Scott \& Chadwick (1924) give figures for Balanus balanoides nauplii and cyprids for the period 
1907-20, and it is of interest to find that even greater variations appear in their records, e.g. more than two thousand times the number of nauplii were recorded in March 1912 than in March 1907.

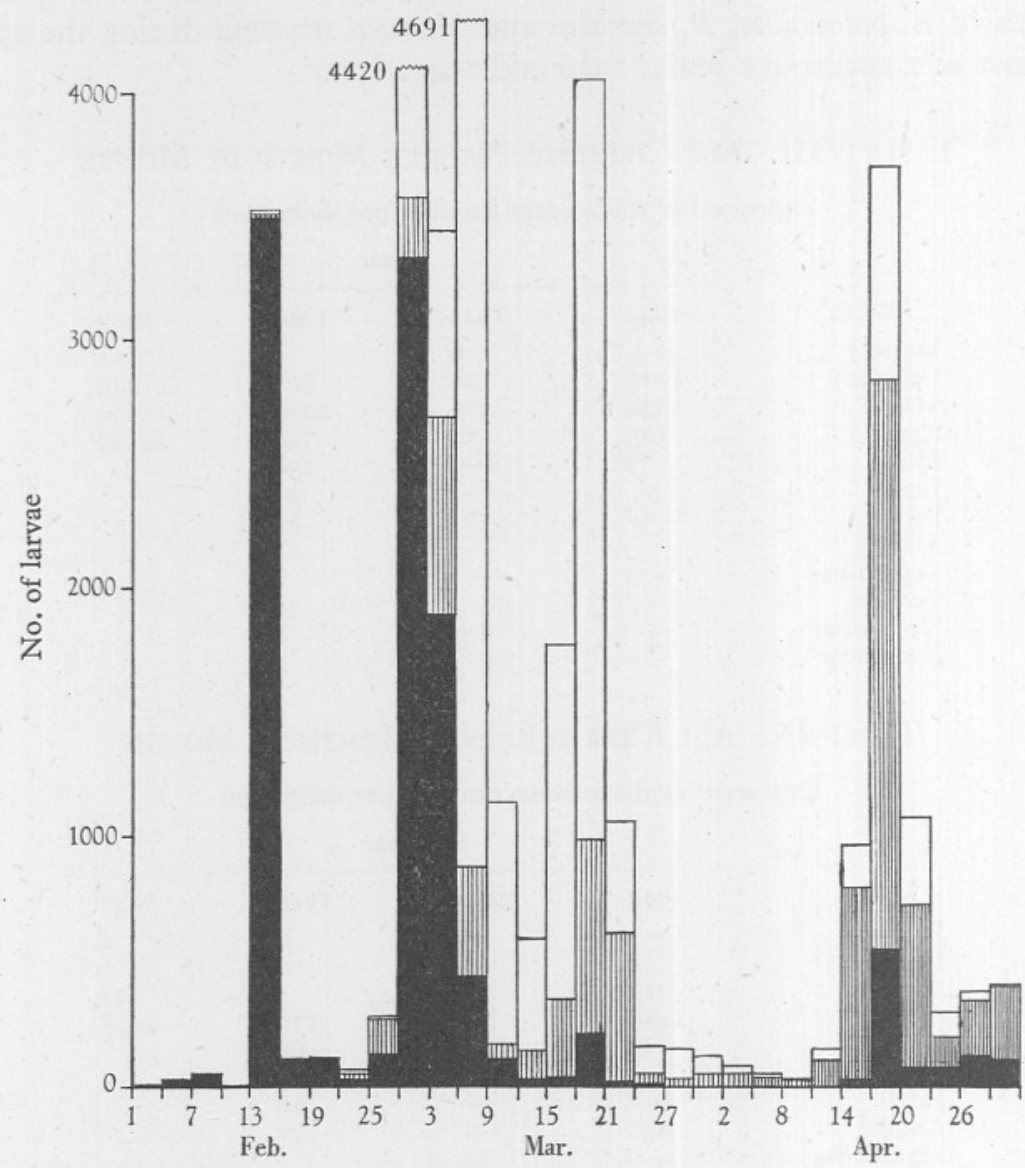

Fig. I4. Occurrence of Cirripede nauplii, Feb.-Apr. I946. The shaded areas within each histogram indicate the numbers of the larvae of Verruca stroemia; the vertically hatched areas the numbers of Balanus crenatus larvae; the remaining areas the numbers of $B$. balanoides larvae.

Direct comparisons between the records obtained in the present survey and those obtained by Johnstone, Scott \& Chadwick (1924) are impossible since fishing conditions were entirely different in the two surveys. One point, however, seems worthy of mention. Johnstone, Scott \& Chadwick (loc. cit. p. 66) drew attention to the great discrepancy between the numbers of nauplii and the numbers of cyprids caught, and attributed this to the destruction of the nauplii during their period of development and to the dispersal of the swarms. 
The discrepancy recorded for Port Erin is certainly very great (mean monthly haul of nauplii (in March) 35,224 ; mean monthly haul of cyprids (in May) 70), much greater than that of the present records, where the mean monthly haul of nauplii in March was I40,985 and the mean monthly haul of cyprids in April was 34,920. (The present records refer, of course, to the larvae of all three

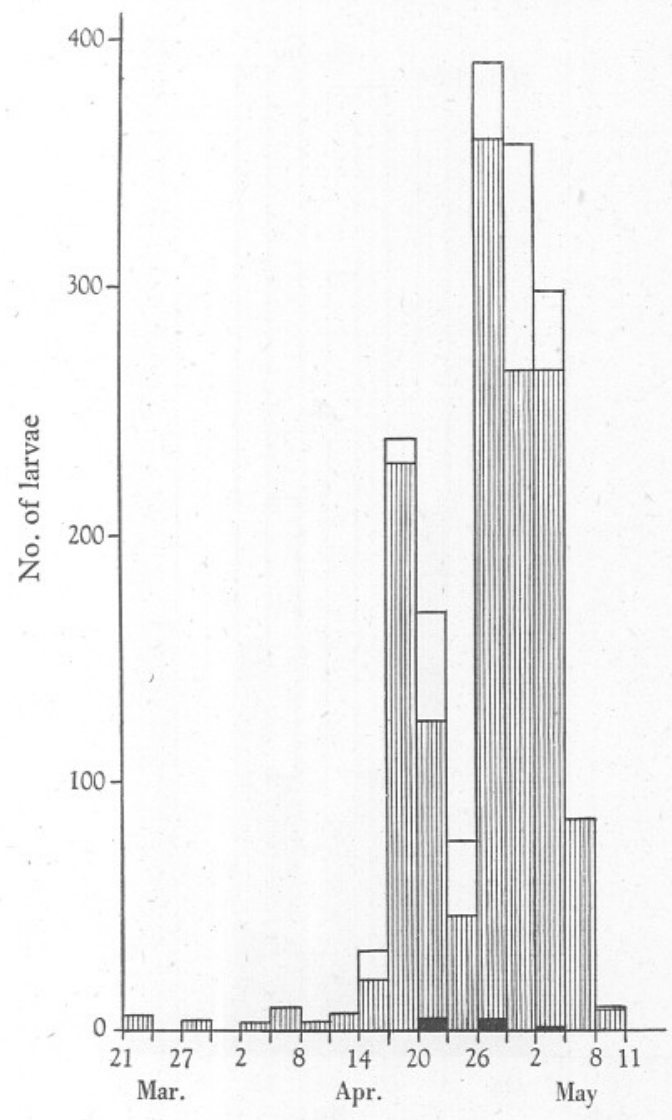

Fig. 15. Occurrence of cyprid larvae, Mar.-May 1946. Shading as in Fig. I4.

species of barnacle but, although Johnstone, Scott \& Chadwick's account refers to their larvae as those of $B$. balanoides, their specific identity was merely inferred from the abundance of this species on the neighbouring shores; it would seem probable that larvae of other species of barnacle were present.) The present series of hauls were all made within a few feet of the shore and perhaps this may be the reason for the smaller discrepancy between the numbers of nauplii and the numbers of cyprids in the present instance, as it is possible that the cyprids tend to occur in their greatest numbers close inshore. 
Some observations have been made on the dates when settlement of $B$. balanoides was first observed at different places. Fish (1925) states that in 1923 the first cyprids of this species appeared at Woods Hole on 8 February, that they were particularly abundant on 5 and 6 March and that they declined in numbers during April. He adds that the season in 1923 coincided exactly with that in 1900 . This record is in general agreement with that of Grave (I933), who

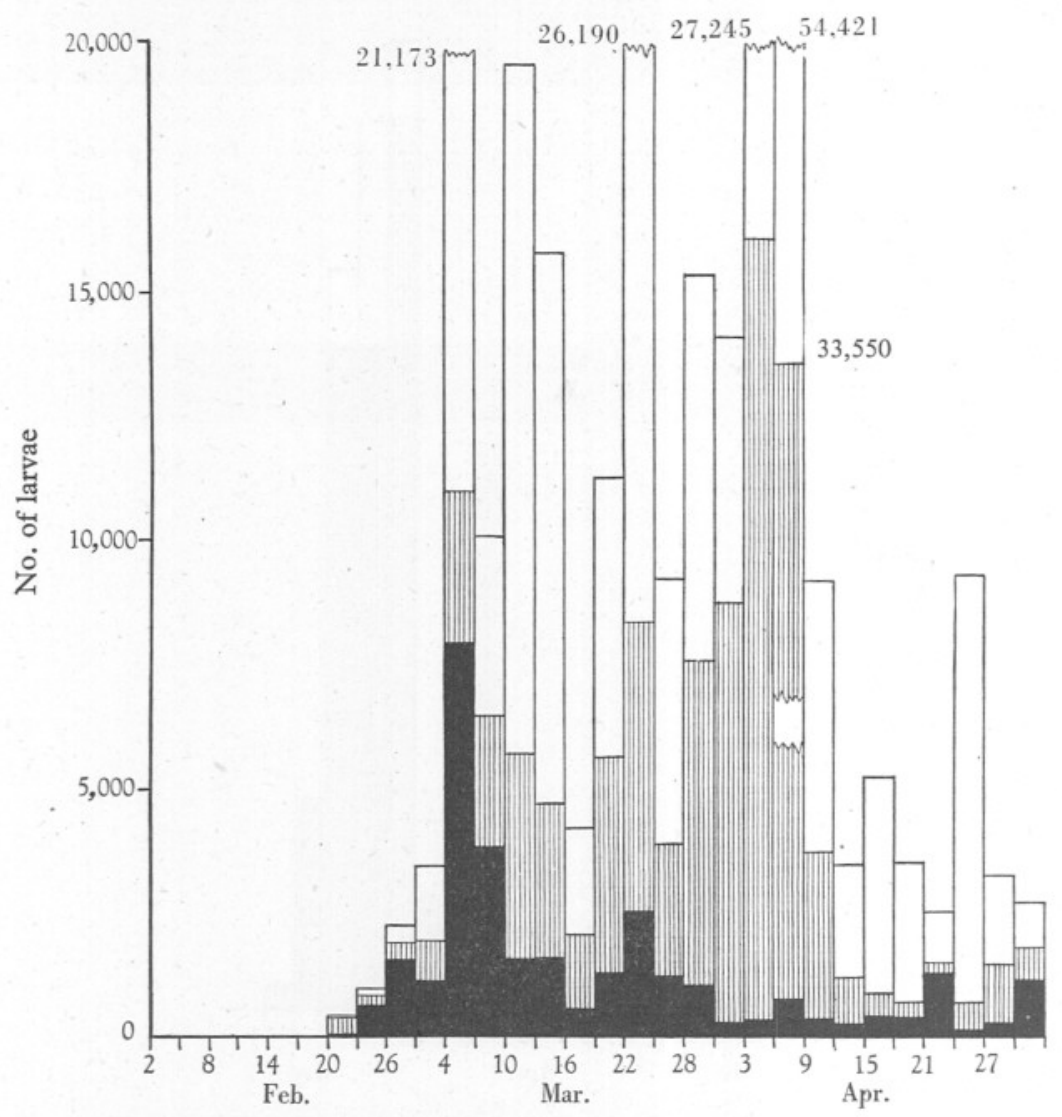

Fig. I6. Occurrence of Cirripede nauplii, Feb.-Apr. I947. Shading as in Fig. I4.

states that metamorphosis takes place between I5 February and I5 March. Moore (1935a) comments on the surprisingly small variation in the date on which the first settled cyprids were observed on the rocks at Port Erin. In 1932 this was 26 April, in I933 and 1934 on 25 April. Runnström (I925) mentions that the first cyprids were observed in Liverpool Bay on 6 April and that these larvae reached their maximum on about I5 April.

Hatton \& Fischer-Piette (1932), however, found considerable variation both in the date when settled cyprids were first recorded and in the length of the 
settlement period at St Malo. In I930 the larvae first settled between 29 March and 2 April and settlement continued for 6 weeks, whereas in I93I settlement first occurred between I5-2I February and 4-8 March, and this process continued for 3 months.

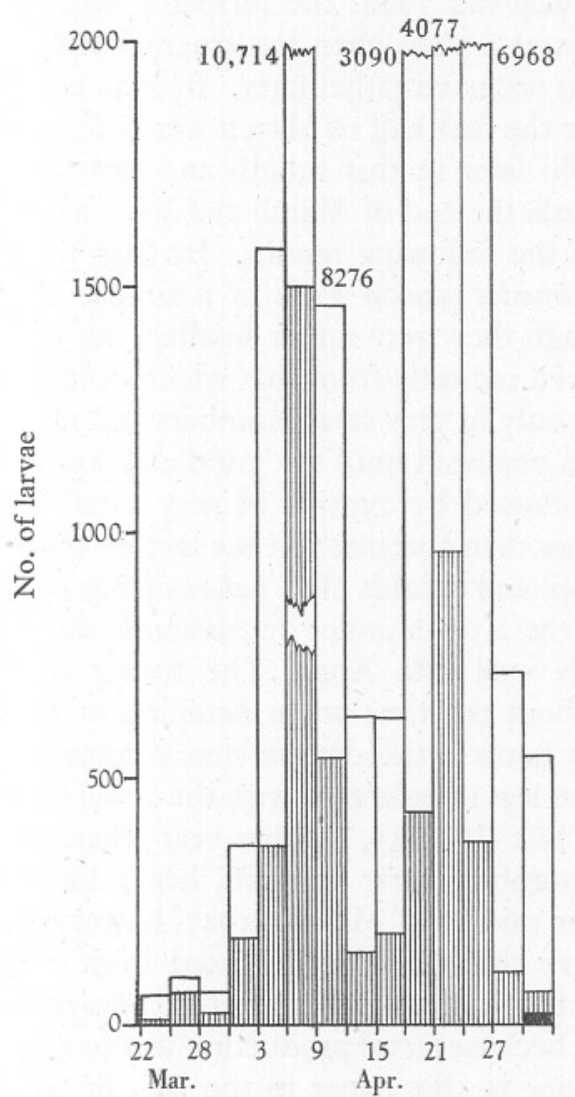

Fig. 17. Occurrence of cyprid larvae, Mar.-Apr. 1947. Shading as in Fig. I4.

The dates on which settlement was first observed and the period of settlement also varied to some extent in the present instance. Details are given below.

Year

I944

I945

I946

I947

\section{Cyprids}

First abundant on 3 April

First abundant on 2 April

A few present from I4 April to the end of the month

Some cyprids present throughout April; only abundant later in month
Settlement

Throughout April

Limited to the first 2 weeks of April

Light settlement over last 2 weeks of April

Light settlement throughout April; slightly heavier towards the end of the month

Thus it would appear that, in some places, settlement of B. balanoides occurs with some regularity on a given date (e.g. Port Erin, Woods Hole) 
whereas at others (St Malo, Millport) variations can occur from year to year. Characteristics have been observed in the course of the present survey which suggest a possible explanation of these differences.

Fig. I8 compares the general features of the planktonic occurrence of B. balanoides for 1944 and 1946; the former a year when heavy settlement occurred and the latter a year when settlement was light and when, in comparison with 1944, it occurred rather later. In 1944 heavy hauls of Ist and 2nd stage nauplii during the first half of March were succeeded by moderate hauls of later-stage nauplii later in that month and early in April. Cyprid larvae first appeared towards the end of March and were moderately abundant until towards the end of the following month. In I946 the hauls over the earlier part of the B. balanoides season were of a similar order to those recorded 2 years earlier (though they were rather smaller) but the situation towards the end of March differed radically from that which occurred in 1944. Late-stage larvae were present only in very small numbers and no cyprid larvae appeared at all. This situation persisted until the middle of April when some later-stage nauplii appeared followed by cyprids in very small numbers. It would be dangerous to do more than speculate on the factors which virtually obliterated the later-stage nauplii and cyprids of B. balanoides in 1946, but the outstanding difference between the 2 years under discussion is the persistence, in I946, of heavy diatom hauls well into April. The spring outburst of Skeletonema usually occurs at about the time when hatching of Balanus balanoides takes place; in I944 heavy hauls of this diatom were confined to a short period in the middle of March and less interference with the larval sequence of $B$. balanoides was apparent (Fig. I8). In I945, another year when cyprids of $B$. balanoides appeared in some numbers early in April, heavy hauls of Skeletonema were again confined to the middle of March. 1947, however, resembled 1946 more closely in that heavy diatom hauls persisted from early March until early April; it seems possible that settlement in 1947 was rather heavier than in the preceding year only because larval production was so much heavier. Reference has been made earlier in this paper to the lack of 'success' of the Balanus balanoides larvae which hatched early in March compared with those which hatched towards the end of the month; it may be surmised that the full development of the earlier 'brood' was appreciably upset by the abundance of diatoms in the water.

It would therefore seem possible that the marked regularity with which settlement occurs at Port Erin is correlated with the absence of heavy diatom hauls there since, according to Johnstone, Scott \& Chadwick (I924), the heaviest diatom hauls do not occur there until May.

The absence of zooplankton in the presence of abundant phytoplankton is a phenomenon which has received a good deal of attention in recent years (Hardy \& Gunther, 1935; Harvey et al. 1935; Lucas, 1936). It is therefore of interest to note this example provided by the larval stages of $B$. balanoides, of 

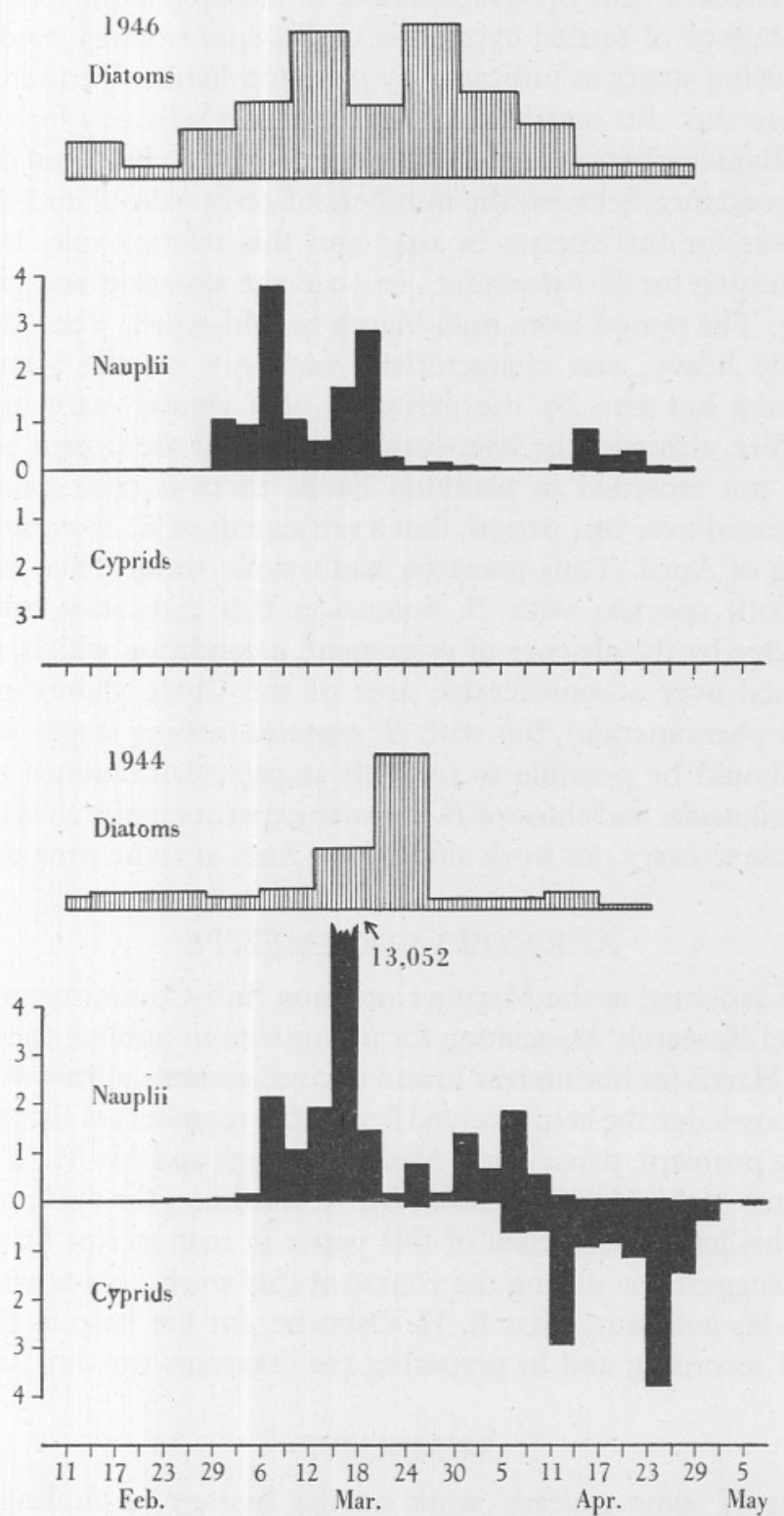

Fig. I8. Occurrence of larval stages of Balanus balanoides, I944 (below) and 1946 (above), compared with estimates of diatom density in the two years. Histograms of the numbers of nauplii present over 3-day periods are shown extending upwards, those of the numbers of cyprids present extending downwards, from the base line. Numbers of nauplii and cyprids expressed in thousands; diatom abundance on an arbitrary scale. 
the apparent effect of heavy phytoplankton on a zooplankton species, particularly as the absence of settled cyprids is useful confirmatory evidence of the absence of settling stages as indicated by plankton hauls. Further, it is also of interest to note that this interference seems far less effective for the larvae of B. crenatus. In an earlier section of this paper attention has been drawn to the closer correspondence between the numbers of early nauplii and the numbers of cyprid larvae for this species in 1947 and this relation may be compared with that obtaining for $B$. balanoides. In 1946 the situation was perhaps even more striking. The period from mid-March to mid-April, when diatom hauls were generally heavy, was characterized not only by the virtual absence of $B$. balanoides but also by the existence of a similar state of affairs for $B$. crenatus. Yet, although the later-stage nauplii and the cyprid larvae of this species were not recorded in plankton hauls, there is clear evidence, from surfaces immersed over this period, that a settlement of B. crenatus occurred at the beginning of April. Thus plankton hauls alone would have indicated the absence of both species: with $B$. balanoides this indication was probably correct (to judge by the absence of settlement, a condition which, it should be noted, obtained over a considerable area of the Clyde shores and was not purely a local phenomenon), but with $B$. crenatus settling stages were, in fact, present. It should be possible to test this suggested difference between the larvae of B. balanoides and those of B. crenatus experimentally; it is hoped that it will be possible to carry out work along these lines at some time in the future.

\section{ACKNOWLEDGEMENTS}

The author is indebted to the Marine Corrosion Sub-Committee of the British Iron and Steel Research Association for permission to publish these notes and to Prof. J. E. Harris for his interest in and encouragement of this work. He also wishes to acknowledge the help received from other members of the team working on the fouling problem, particularly Miss J. C. Mott and Mr M. W. H. Bishop. To the Director of the Marine Station, Mr R. Elmhirst, the author is indebted, not only for his helpful criticism of this paper in manuscript but also for his many useful suggestions during the course of this work. Acknowledgement is also made to his assistant, Miss E. H. Osborne, for her help in the labour of counting and recording and in preparing the diagrams for this paper.

\section{SUMMARY}

In the course of some 4 years' work on the biology of fouling organisms, observations have been made on aspects of the general biology of Balanus balanoides, B. crenatus and Verruca stroemia.

Observations on the state of development of the ova within the mantle cavity of $B$. balanoides and of the occurrence of the larvae in the plankton indicate that hatching takes place during the first fortnight in March, that the 
later-stage nauplii are abundant during the second half of that month and that the cyprid larvae may become abundant during April. The larval sequence is not always completed successfully; conditions which seem inimical are discussed.

Factors which seem to be of importance in affecting settlement of B. balanoides are discussed. The presence of other organisms is an adverse factor, though the potency of this factor is probably not the same for all organisms; the presence of slime can prevent settlement and, though evidence can be quoted in support of heavier settlement on shaded surfaces, it is emphasized that the operation of other factors may have brought about this result. The proportion of the tidal cycle during which current speeds are not too high to prevent settlement seems likely to be important.

Provided that other conditions are favourable $B$. balanoides settles readily on surfaces continuously immersed and individuals which settle under these conditions grow more rapidly, at least for the first few months after settlement, than their contemporaries on the shore.

The larvae of $B$. crenatus appear in the plankton rather earlier than those of $B$. balanoides, but the time taken to complete the larval sequence from the Ist stage nauplius to the cyprid is roughly the same as that for the latter species, namely I month. In B. crenatus, however, hatching is not limited to a short period during March but continues at intervals through the summer. There are indications that the successful completion of the larval sequence of this species is less affected by an abundance of phytoplankton than is that of $B$. balanoides.

Settlement of $B$. crenatus is periodic and individuals which settle early in the spring can attain practically their full size $(28-30 \mathrm{~mm}$. basal length) during the same season. Growth during the summer takes place at average rates which vary from 0.1 to $0.2 \mathrm{~mm}$. increase in basal length per day. Growth is negligible during the winter months.

Specimens of B. crenatus which settle early in April contain developing ova by the beginning of July, so that spring-settled forms can produce larvae which themselves may settle before the end of the summer.

Observations on Verruca stroemia have been limited to the occurrence of the larvae in the plankton. Like those of Balanus crenatus, the larvae of Verruca stroemia are present at intervals through the summer. Early-stage nauplii of this species may dominate the plankton early in the year, but no correspondingly heavy hauls of later-stage nauplii have been recorded. Possible explanations of this discrepancy are discussed. The cyprid never occurs in any numbers in surface hauls.

Incidental observations on the planktonic occurrence of the nauplii of Sacculina (probably S. carcini) and of Peltogaster paguri are given.

Details are given of the abundance of all Cirripede larvae in the plankton for the years 1944-47 which emphasize the extent of variation that can occur from year to year. 


\section{REFERENCES}

BASsindale, R., I936. The developmental stages of three English barnacles, Balanus balanoides (Linn.), Chthamalus stellatus (Poli) and Verruca stroemia (O. F. Müller). Proc. Zool. Soc. Lond., I936, pp. 57-74.

Boschмa, H., I927. Bermerkungen über Rhizocephalen des Golfes von Neapel. Publ. del. Staz. Zool. Napoli, Vol. vIII, pp. 26I-72.

Darwin, C., I854. Monograph of the Cirripedia. Balanidae. Ray Society. London.

ELMHIRST, R., I923. Notes on the breeding and growth of marine animals in the Clyde sea area. Ann. Rep. Scot. Mar. Biol. Assoc., I922.

Fischer-Piette, E., I932. Sur l'habitat des Cirripèdes Balanus crenatus Brug. et Verruca stroemia O. F. Müller. Bull. Lab. Maritime St Servan, No. 8, pp. 8-II.

Fish, C. J., I925. Seasonal distribution of the plankton of the Woods Hole region. Bull. U.S. Bur. Fish. Washington, Vol. xLI, pp. 9I-I79.

Foxon, G. E. H., 1940. Notes on the life history of Sacculina carcini Thompson. fourn. Mar. Biol. Assoc., Vol. xxiv, pp. 253-64.

Grave, B. H., I933. Rate of growth, age at sexual maturity and duration of life of certain sessile organisms at Woods Hole, Massachusetts. Biol. Bull. Woods Hole, Vol. LXV, pp. 275-386.

HARDY, A. C. \& GunTHER, E. R., I935. The plankton of the South Georgia whaling grounds and adjacent waters, I926-27. Discovery Repts., Vol. XI, pp. I-456.

Harvey, H. W., Cooper, L. H. N., Lebour, M. V. \& Russell, F. S., I935. Plankton production and its control. Fourn. Mar. Biol. Assoc., Vol. xx, pp. 407-42.

Hatton, H. \& Fischer-Piette, E., I932. Observations et expériences sur le peuplement des côtes rocheuses par les Cirripèdes. Bull. Inst. océanogr. Monaco, No. 592.

Herz, L. E., I933. The morphology of the later stages of Balanus crenatus Brugière. Biol. Bull. Woods Hole, Vol. LxIv, pp. 432-42.

Hoek, P. P. C., I909. Die Cirripedien des nordischen Planktons. Nordisches Plankton. Bd. IV, No. 8, pp. 265-331.

Johnstone, J., Scott, A. \& Chadwick, H. C., I924. The Marine Plankton. Liverpool.

LUCAS, C. E., I936. On certain inter-relations between phytoplankton and zooplankton under experimental conditions. Conseil Per. Internat. p. l'Explor. de la Mer, Fourn. du Conseil, Vol. xI, pp. 343-62.

MACDONALD, R., I927. Irregular development in the larval history of Meganyctiphanes norvegica. Fourn. Mar. Biol. Assoc., Vol. xiv, pp. 785-94.

McDougall, K. D., I943. Sessile marine invertebrates at Beaufort, North Carolina. Ecol. Monog., Vol. xIII, pp. $32 \mathrm{I}-74$.

Moore, H. B., I934. The biology of Balanus balanoides. I. Growth rate and its relation to size, season and tidal level. Fourn. Mar. Biol. Assoc., Vol. xIx, pp. $85 \mathrm{I}-68$.

_ I935 a. The biology of Balanus balanoides. III. The soft parts. Fourn. Mar. Biol. Assoc., Vol. xx, pp. 263-77.

I 1935 b. The biology of Balanus balanoides. IV. Relation to environmental factors. Fourn. Mar. Biol. Assoc., Vol. xx, pp. 279-307.

Moore, H. B. \& Kitching, J. A., I939. The biology of Chthamalus stellatus (Poli). fourn. Mar. Biol. Assoc., Vol. xxIII, pp. 52 I-4I.

Neu, W., I933. Der Einfluss des Farbtons der Unterlage auf die Besiedlung mit Balanus da Costa und Spirorbis Mont. Internat. Revue des ges. Hydrobiol. $u$. Hydrographie, Bd. xxvIII, Heft 3/4, pp. 228-46. 
Nilsson-Cantell, C. A., I92I. Cirripedien studien. Zool. Bidr. Uppsala, Vol. vII, pp. $75-378$.

Pomerat, C. M. \& ReIner, E. R., I942. The influence of surface angle and of light in the attachment of barnacles and of other sedentary organisms. Biol. Bull. Woods Hole, Vol. LXxxII, pp. I4-25.

Pomerat, C. M. \& WeISS, C. M., I946. The influence of texture and composition of surface in the attachment of sedentary marine organisms. Biol. Bull. Woods Hole, Vol. xCI, pp. 57-65.

Pryor, M. G. M., I940. On the hardening of the cuticle of insects. Proc. Roy. Soc., Lond. (B), Vol. cxxviII, pp. 393-407.

Pyefinch, K. A., I948. Methods of identification of the larvae of Balanus balanoides (Linn.), B. crenatus Brug. and Verruca stroemia O. F. Müller. Fourn. Mar. Biol. Assoc., Vol. xxvII, pp.

ReINHARD, E. G., I946. Rhizocephala from New England and the Grand Banks. fourn. Wash. Acad. Sci., Vol. xxxvi, pp. I27-3I.

RunNSTRÖM, S., 1925. Zur Biologie und Entwicklung von Balanus balanoides (Linné). Bergens Mus. Aarbok., Naturv. Raekke, Nr. 5.

Scotт, T., I90I. Land, fresh-water and marine Crustacea. Fauna, Flora and Geology of the Clyde Area. Glasgow.

SMITH, F. G. WALTON, I946. Effect of water currents upon the attachment and growth of barnacles. Biol. Bull. Woods Hole, Vol. xc, pp. 5I-70.

Topsent, E., igir. Croissance et mort des balanes à Luc-sur-Mer. Ann. Inst. océanogr., T. II, Fasc. 6.

VISSCHER, J. P., I928. Reactions of the cyprid larvae of barnacles at the time of attachment. Biol. Bull. Woods Hole, Vol. LIv, pp. 327-35.

VISSCHER, J. P. \& LUCE, R. H., I928. Reactions of the cyprid larvae of barnacles to light with special reference to spectral colours. Biol. Bull. Woods Hole, Vol. LIv, pp. 336-50.

YONGE, C. M., 1938. The nature and significance of the membranes surrounding the developing eggs of Homarus vulgaris and other Decapoda. Proc. Zool. Soc. Lond., Ser. A, Vol. cVII, pp. 499-5I7. 